\title{
Tetrel and Pnictogen Bonds Complement Hydrogen and Halogen Bonds in Framing the Interactional Landscape of Barbituric Acids
}

\author{
Vijith Kumar, Patrick Scilabra, Peter Politzer, Giancarlo Terraneo, Andrea Daolio, \\ Francisco Fernandez-Palacio, Jane S. Murray,* and Giuseppe Resnati*
}

Cite This: Cryst. Growth Des. 2021, 21, 642-652

Read Online

\section{ACCESS | Llll Metrics \& More | 回 Article Recommendations | (s) Supporting Information}

ABSTRACT: Experimental and theoretical studies of fluoro-, chloro-, and bromo-substituted derivatives of barbituric acid and indandione show that imide protons form short hydrogen bonds and bromine or, to a lesser extent, chlorine atoms form halogen bonds. The imide nitrogen atoms act as effective pnictogen bond donors, while $\mathrm{C}\left(\mathrm{sp}^{2}\right)$ and $\mathrm{C}\left(\mathrm{sp}^{3}\right)$ atoms act as tetrel bond donors; the resulting $\mathrm{N} \cdots \mathrm{O}$ and $\mathrm{C} \cdots \mathrm{O}$ close interactions are a distinctive feature

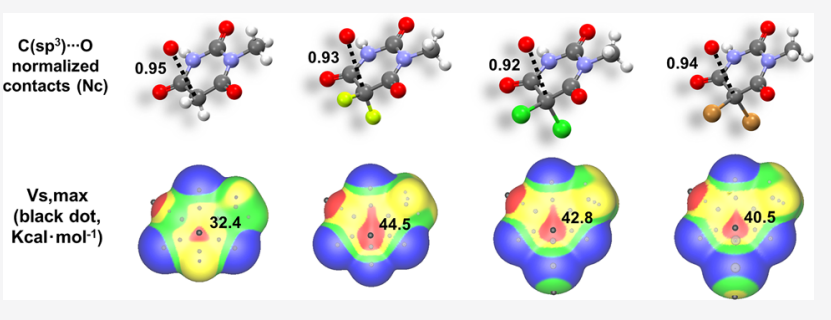
of crystal lattices in all compounds. Importantly, halogen atoms promote the electrophilicity of $\mathrm{C}\left(\mathrm{sp}^{3}\right)$ sites and favor the formation of $\mathrm{C}\left(\mathrm{sp}^{3}\right) \cdots \mathrm{O}$ close contacts. Oxygen atoms of carbonyl groups of barbituric and indandione units or of water molecules function as the interaction acceptor sites: namely, they donate electron density to hydrogen, halogen, nitrogen, and carbon atoms. Modeling of various barbituric acid derivatives indicates that the positive electrostatic potentials of $\pi$-holes orthogonal to the $\mathrm{C}\left(\mathrm{sp}^{2}\right)$ carbons and $\sigma$-holes on the elongation of quasi-axial $\mathrm{F} / \mathrm{Cl} / \mathrm{Br}-\mathrm{C}\left(\mathrm{sp}^{3}\right)$ bonds merge to produce a single well-defined point of the most positive electrostatic potential on one face of the barbituric acids. This single local maximum of the potential on the molecular face is close to the site occupied by the oxygen forming the $\mathrm{C}\left(\mathrm{sp}^{3}\right) \cdots \mathrm{O}$, and $\mathrm{C}\left(\mathrm{sp}^{2}\right) \cdots \mathrm{O}$, short contacts observed in crystals.

\section{INTRODUCTION}

An in-depth understanding of supramolecular interactions and their role in driving or affecting molecular recognition phenomena is crucial in diversified fields of chemistry and biology, ranging from the photophysical properties of lightemitting diodes to structure-based drug design. ${ }^{1,2}$ Since carbon atoms are ubiquitous in organic compounds, the elucidation of short contacts involving carbon moieties is of paramount importance.

Covalently bonded atoms of groups 13-18 of the Periodic Table commonly have anisotropic distributions of electronic density. This results in regions, on the molecular surface, in which the electronic density is low and the electrostatic potential is frequently positive. ${ }^{3}$ These positive regions tend to behave as electrophilic sites (Lewis acids) and to interact attractively with electron-rich sites, for instance $\pi$-bonds, lone pairs on neutral atoms, and anions. Such sites act as nucleophiles (Lewis bases).

When the region of reduced electronic density is localized approximately along the extension of a $\sigma$ bond to an atom, it is labeled a $\sigma$-hole on that atom. ${ }^{4}$ When it is above and below a planar portion of a molecule, it is called a $\pi$-hole. ${ }^{5}$ The interactions of nucleophiles with the positive electrostatic potentials that are often associated with $\sigma$ - and $\pi$-holes are known as $\sigma$-hole interactions and $\pi$-hole interactions. ${ }^{6}$

Some features of these interactions are quite similar regardless of the group of the Periodic Table to which the electrophilic site belongs. For instance, the strength of the interactions of a given nucleophile with electrophilic sites on the different atoms within a group increases with the polarizability of the atom and with the electron-withdrawing abilities of the residues bound closely to it. ${ }^{7,8}$

Other features vary with the group to which the electrophilic site belongs. For instance, $\sigma$-hole interactions are more likely to deviate somewhat from the extension of the $\sigma$-covalent bond that generates the $\sigma$-hole when the $\sigma$-hole is on an atom of groups 15 and 16 than when it is an atom of groups $14 \mathrm{smf}$ 17. ${ }^{9}$ A systematic terminology recognizes these differences and designates interactions by referring to the name of the group of the electrophilic site. ${ }^{10,11}$ The halogen bond $(\mathrm{HaB})^{12}$ and the chalcogen bond (ChB), ${ }^{13,14}$ which occur when the electrophile is an atom of groups 17 and 16, are the most widely investigated interactions of this set. The triel bond $(\operatorname{TrB}),{ }^{15}$ the pnictogen bond $(\mathrm{PnB}),{ }^{16,17}$ and also the noble-gas bond $(\mathrm{NgB}),{ }^{18}$ wherein the electrophilic site is in groups 13,15 , and 18 , are receiving growing interest. The tetrel bond $(\mathrm{TtB})$ model for interactions where the electrophile is in group 14,

Received: October 21, 2020

Revised: December 8, 2020

Published: December 16, 2020 
was first proposed in $2009^{19}$ and rapidly reached the center stage, $^{20,21}$ probably because $\mathrm{TtBs}$ may be ubiquitous interactions, due to the widespread presence of carbon in organic derivatives, and may be related to some key chemical phenomena such as $\mathrm{S}_{\mathrm{N}} 2$ reactions $^{22}$ and hydrophobic interactions. $^{23}$

Most of the interactions that have been interpreted as $\sigma$ - or $\pi$-hole, involving attractions between regions of opposite electrostatic potential, were already known from earlier experimental work. For instance, the formation of the $I_{2}-$ ammonia adduct, now understood as a halogen-bonded system, ${ }^{24}$ was first reported in a paper from Gay-Lussac's laboratory as early as $1814,{ }^{25}$ and the $\mathrm{SO}_{2}$-amine adducts, now understood as chalcogen-bonded systems, ${ }^{26}$ were already described in an article from Hofmann's laboratory in $1843 .^{27}$

The same is true for TtBs involving $\mathrm{C}\left(\mathrm{sp}^{2}\right)$ atoms. The seminal work of Bürgi and Dunitz in the $1970 \mathrm{~s}^{28}$ identified the attractive interaction between electron-rich sites and the partially positive $\mathrm{C}\left(\mathrm{sp}^{2}\right)$ atoms of carbonyl derivatives as a central theme of molecular recognition. A variety of such attractive interactions, characterized by quite different relative arrangements of interacting partners, have subsequently been recognized: ${ }^{29}$ e.g., parallel dipolar interactions pairing a permanent carbonyl dipole with another dipole and the orthogonal Coulombic interactions between a carbonyl carbon and a lone pair or an anion. ${ }^{30,31}$ All of these are now understood as $\pi$-hole interactions at carbons. ${ }^{5,6}$ In contrast, adducts formed due to $\mathrm{C}\left(\mathrm{sp}^{3}\right) \cdots$ nucleophile attractive interactions began to be a focus of studies on recognition phenomena only early in this century, after the publication of papers proposing to extend to group 14 elements, ${ }^{5,19}$ the mindset developed in relation to group 17 elements. ${ }^{32-35}$ In very recent years, papers on quantum calculations on these interactions, ${ }^{36,37}$ some combined with mining the Cambridge Structural Database (CSD) and the Protein Data Bank (PDB), ${ }^{38-40}$ were published and unequivocally correlated the directionalities of the interactions with the approach of the nucleophiles to the $\sigma$-holes at carbons. In contrast, experimental studies on $\mathrm{C}\left(\mathrm{sp}^{3}\right) \cdots$ nucleophile interactions have been few ${ }^{41-43}$ and have frequently been limited to charge-density analyses. ${ }^{44}$

Accordingly we decided to assess experimentally the potential of $\mathrm{C}\left(\mathrm{sp}^{3}\right) \cdots$ nucleophile $\mathrm{TtBs}$ in crystal engineering. ${ }^{45}$ The study of intermolecular interactions in chloranil, ${ }^{46}$ alloxan, ${ }^{47}$ and triketoindane ${ }^{48}$ afforded probably the first indications of orthogonal $\mathrm{C}=\mathrm{O} \cdots \mathrm{C}=\mathrm{O}$ close contacts, an important subclass of $\mathrm{C}\left(\mathrm{sp}^{2}\right) \cdots$ nucleophile TtBs. We considered that the more electron withdrawing a group $\sigma$-bonded to carbon, the more extended and positive the carbon $\sigma$-hole and the closer and stronger the resulting $\sigma$-hole interactions. ${ }^{3-5} \mathrm{We}$ thus focused our attention on 5,5-dihalobarbituric acid derivatives $1 \mathbf{a}-\mathbf{m}$, which can be considered alloxan analogues wherein the $\mathrm{C} 5=\mathrm{O}$ group is replaced by a $\mathrm{CX}_{2}$ moiety $(\mathrm{X}=\mathrm{F}$, $\mathrm{Cl}, \mathrm{Br}$ ) (Scheme 1). Introduction on $\mathrm{C} 5$ of electronwithdrawing halogen atoms was used to boost the electrophilic character of this $\mathrm{sp}^{3}$ atom and to favor its involvement in $\mathrm{C}\left(\mathrm{sp}^{3}\right) \cdots \mathrm{O}$ intermolecular interactions.

An interesting consequence of replacing the $\mathrm{C}(5) \mathrm{H}_{2}$ hydrogens by halogen atoms $\mathrm{X}$ is that the $\mathrm{CX}_{2}$ carbon moves out of the ring plane. As a result, whereas the two $\mathrm{C}-\mathrm{H}$ bonds at $\mathrm{C} 5$ in the parent barbituric acids are directed symmetrically above and below the plane, in the halogenated derivatives one of the $\mathrm{C}-\mathrm{X}$ bonds is quasi-equatorial and the
Scheme 1. Structural Formulas of 5,5-Dihalobabrbituric Acids $1 \mathrm{a}-\mathrm{m}$ and Indandione Derivative 2

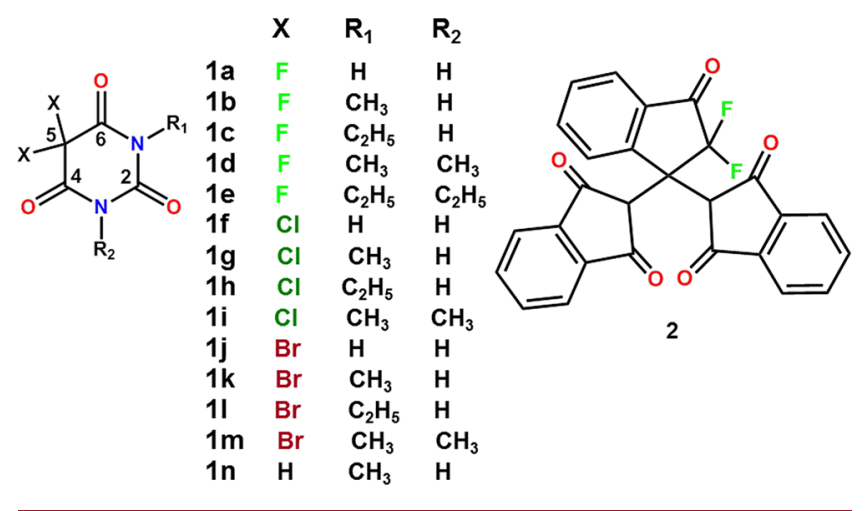

other is quasi-axial. This paper describes the single-crystal Xray structures of barbituric acid derivatives $\mathbf{1 a}-\mathbf{m}$, which feature both $\mathrm{C}\left(\mathrm{sp}^{2}\right) \cdots \mathrm{O}$ and $\mathrm{C}\left(\mathrm{sp}^{3}\right) \cdots \mathrm{O}$ close contacts ${ }^{49-52}$ wherein carbon and oxygen atoms serve as electrophilic and nucleophilic sites, respectively. Modeling of these derivatives 1 brings out an unusual and interesting point. On the face opposite to the quasi-axial halogen, the positive electrostatic potentials of $\pi$-holes orthogonal to the $\mathrm{C}\left(\mathrm{sp}^{2}\right)$ carbons merge with the positive electrostatic potential of $\sigma$-holes on the elongation of quasi-axial $\mathrm{X}-\mathrm{C}\left(\mathrm{sp}^{3}\right)$ bonds. This produces a single well-defined point of the most positive electrostatic potential on the face, and this point is located close to C5. On the opposite face, a similar merging is observed of the positive electrostatic potentials of $\pi$-holes orthogonal to the $\mathrm{C}\left(\mathrm{sp}^{2}\right)$ carbons and the positive electrostatic potential of $\sigma$-holes on the elongation of quasi-equatorial $\mathrm{X}-\mathrm{C}\left(\mathrm{sp}^{3}\right)$ bonds and a single point of less positive potential is generated that is quite close to C2. Clearly, the directionalities of the two geminal X$\mathrm{C}\left(\mathrm{sp}^{3}\right)$ bonds affect the electrostatic potential at these most positive points and their locations. These positive potentials correlate nicely with the $\mathrm{C}\left(\mathrm{sp}^{2}\right) \cdots \mathrm{O}$ and $\mathrm{C}\left(\mathrm{sp}^{3}\right) \cdots \mathrm{O}$ close contacts observed in the crystal structures. Importantly, these findings are an experimental validation of the ability of $\mathrm{C}\left(\mathrm{sp}^{3}\right)$ atoms to function as electrophilic sites and to affect the formation of close contacts with electron-rich sites, namely $\mathrm{TtBs}$, that influence the conformation and crystal packing of organic derivatives.

It has been frequently considered that $\mathrm{C}\left(\mathrm{sp}^{3}\right) \cdots$ nucleophile contacts may result from or be associated with the formation of hydrogen bonds (HBs) involving the partially positive hydrogen atoms bound to the carbon atom. ${ }^{38,44}$ The $\mathrm{C}\left(\mathrm{sp}^{3}\right)$ atom forming the close $\mathrm{C}\left(\mathrm{sp}^{3}\right) \cdots \mathrm{O}$ contacts in barbituric derivatives 1 bears no hydrogen atoms; thus, the observed close $\mathrm{C} \cdots \mathrm{O}$ separations confirm the inherent tendency of $\mathrm{C}\left(\mathrm{sp}^{3}\right)$ atoms bearing electron-withdrawing groups to function as $\mathrm{TtB}$ donor sites in the absence of "auxiliary" HBs.

\section{EXPERIMENTAL SECTION}

Materials and Methods. The starting materials (barbituric acid, 1,3-dimethybarbituric acid, and 1,3-indandione) were purchased from Sigma-Aldrich. Commercial AR grade solvents were purchased from Merck, TCI (Europe and Japan), and Apollo Scientific and used without any further purification for synthesis and crystallization.

IR spectra were obtained using a Nicolet Nexus FT-IR spectrometer equipped with a UATR unit. Melting points were determined with a Reichert instrument by observing the melting and crystallizing process through a polarizable optical microscope. 
Table 1. Summary of Crystal Data and Structure Refinement for Compounds 1 and 2

\begin{tabular}{|c|c|c|c|c|c|c|c|c|c|c|}
\hline \multicolumn{2}{|r|}{$1 \mathrm{a}$} & $1 b$ & \multicolumn{2}{|r|}{ 1c } & \multicolumn{2}{|c|}{ 1d } & \multicolumn{2}{|l|}{ 1e } & $1 \mathrm{~g}$ & $1 \mathrm{~h}$ \\
\hline empirical formula & $\mathrm{C}_{4} \mathrm{H}_{2} \mathrm{~N}_{2} \mathrm{O}_{3} \mathrm{~F}_{2}$ & $\mathrm{C}_{5} \mathrm{H}_{4} \mathrm{~F}_{2} \mathrm{~N}_{2} \mathrm{O}_{3}$ & \multicolumn{2}{|c|}{$\mathrm{C}_{6} \mathrm{H}_{6} \mathrm{~F}_{2} \mathrm{~N}_{2} \mathrm{O}_{3}$} & \multicolumn{2}{|c|}{$\mathrm{C}_{6} \mathrm{H}_{6} \mathrm{~F}_{2} \mathrm{~N}_{2} \mathrm{O}_{3}$} & \multicolumn{2}{|c|}{$\mathrm{C}_{8} \mathrm{H}_{10} \mathrm{~F}_{2} \mathrm{~N}_{2} \mathrm{O}_{3}$} & $\mathrm{C}_{5} \mathrm{H}_{6} \mathrm{Cl}_{2} \mathrm{~N}_{2} \mathrm{O}_{4}$ & $\mathrm{C}_{6} \mathrm{H}_{6} \mathrm{Cl}_{2} \mathrm{~N}_{2} \mathrm{O}_{3}$ \\
\hline formula wt & 164.08 & 178.10 & \multicolumn{2}{|c|}{192.13} & \multicolumn{2}{|c|}{192.13} & \multicolumn{2}{|c|}{220.18} & & 243.04 \\
\hline temp $(\mathrm{K})$ & 93.15 & $103(2)$ & \multicolumn{2}{|c|}{296.15} & \multicolumn{2}{|l|}{$100(2)$} & \multicolumn{2}{|l|}{103.15} & 100 & 100 \\
\hline cryst syst & orthorhombic & tetragonal & \multicolumn{2}{|c|}{ trigonal } & \multicolumn{2}{|c|}{ orthorhombic } & \multicolumn{2}{|c|}{ orthorhombic } & monoclinic & triclinic \\
\hline space group & $P 2_{1} 2_{1} 2_{1}$ & $I \overline{4}$ & $R \overline{3}$ & & $\mathrm{Pna}_{1}$ & & Pnma & & $\mathrm{P} 2_{1} / \mathrm{n}$ & $P \overline{1}$ \\
\hline$a(\AA)$ & $6.5281(10)$ & $13.2141(9)$ & 23.3 & $3(4)$ & 19.3227 & $(8)$ & $7.476(3)$ & & $8.032(13)$ & $5.4465(4)$ \\
\hline$b(\AA)$ & $7.7341(12)$ & $13.2141(9)$ & 23.3 & $37(4)$ & 8.3366 & & $16.400(8)$ & & $6.9127(12)$ & $8.3852(7)$ \\
\hline$c(\AA)$ & $11.000(2)$ & $7.6784(6)$ & 7.54 & $38(14)$ & 19.3333 & (9) & $7.834(4)$ & & $16.070(2)$ & $10.6465(9)$ \\
\hline$\alpha(\operatorname{deg})$ & 90 & 90 & 90 & & 90 & & 90 & & 90 & $97.424(4)$ \\
\hline$\beta(\operatorname{deg})$ & 90 & 90 & 90 & & 90 & & 90 & & $100.077(8)$ & $103.938(4)$ \\
\hline$\gamma(\operatorname{deg})$ & 90 & 90 & 120 & & 90 & & 90 & & 90 & $92.490(4)$ \\
\hline volume $\left(\AA^{3}\right)$ & $555.39(16)$ & $1340.7(2)$ & 356 & $.4(14)$ & 3114.3( & & $960.5(8)$ & & $878.5(2)$ & $466.55(7)$ \\
\hline Z & 4 & 8 & 18 & & 16 & & 4 & & 4 & 2 \\
\hline$\rho\left(\mathrm{g} / \mathrm{cm}^{3}\right)$ & 1.962 & 1.765 & 1.61 & & 1.639 & & 1.523 & & 1.732 & 1.730 \\
\hline$\mu\left(\mathrm{mm}^{-1}\right)$ & 0.207 & 0.179 & 0.15 & & 0.161 & & 0.141 & & 0.707 & 0.671 \\
\hline$F(000)$ & 328.0 & 720.0 & 176 & & 1568.0 & & 456.0 & & 424.0 & 228.0 \\
\hline no. of rflns collected & 12559 & 2402 & 109 & & 44097 & & 5385 & & 24285 & 2149 \\
\hline goodness of fit on $F^{2}$ & 1.005 & 1.028 & 2.41 & & 1.029 & & 1.149 & & 1.027 & 1.218 \\
\hline final $R$ indexes $(I>2 \sigma(I))$ & $\begin{array}{l}\mathrm{R} 1=0.0442, \\
\mathrm{w} R 2=0.0760\end{array}$ & $\begin{array}{l}\mathrm{R} 1=0.0284 \\
\mathrm{w} R 2=0.0681\end{array}$ & $\begin{array}{c}\mathrm{R} 1 \\
\mathrm{w}\end{array}$ & $\begin{array}{l}0.1472 \\
2=0.4504\end{array}$ & $\begin{array}{c}\mathrm{R} 1=0 \\
\mathrm{wR} 2\end{array}$ & $\begin{array}{l}0390, \\
=0.0956\end{array}$ & $\begin{array}{l}\mathrm{R} 1=0.05 \\
\mathrm{wR} 2=0\end{array}$ & $\begin{array}{l}4, \\
1138\end{array}$ & $\begin{array}{l}\mathrm{R} 1=0.0260 \\
\mathrm{wR} 2=0.0577\end{array}$ & $\begin{array}{l}\mathrm{R} 1=0.0346, \\
\mathrm{wR} 2=0.0920\end{array}$ \\
\hline final $R$ indexes (all data) & $\begin{array}{l}\mathrm{R} 1=0.0750 \\
\mathrm{wR} 2=0.0852\end{array}$ & $\begin{array}{l}\mathrm{R} 1=0.0305 \\
\mathrm{wR} 2=0.0696\end{array}$ & $\mathrm{R} 1$ & $\begin{array}{l}0.1654 \\
2=0.4770\end{array}$ & $\begin{array}{l}\mathrm{R} 1=0 \\
\quad \mathrm{wR} 2\end{array}$ & $\begin{array}{l}0468, \\
=0.1002\end{array}$ & $\begin{array}{l}\mathrm{R} 1=0.11 \\
\quad \mathrm{wR} 2=0\end{array}$ & $\begin{array}{l}8 \\
1307\end{array}$ & $\begin{array}{l}\mathrm{R} 1=0.0357 \\
\mathrm{wR} 2=0.0610\end{array}$ & $\begin{array}{l}\mathrm{R} 1=0.0450 \\
\mathrm{wR} 2=0.1086\end{array}$ \\
\hline CCDC no. & 2006593 & 2006589 & 200 & 588 & 200660 & & 2006590 & & 2006592 & 2006591 \\
\hline & $\mathbf{l i}$ & $1 \mathbf{k}$ & & 11 & & & $1 \mathrm{~m}$ & & ln & 2 \\
\hline empirical formula & $\mathrm{C}_{6} \mathrm{H}_{6} \mathrm{Cl}_{2} \mathrm{~N}_{2} \mathrm{O}_{3}$ & $\mathrm{C}_{5} \mathrm{H}_{6} \mathrm{Br}_{2} \mathrm{~N}_{2} \mathrm{O}_{4}$ & & $\mathrm{C}_{6} \mathrm{H}_{6} \mathrm{Br}_{2} \mathrm{~N}_{2}$ & & $\mathrm{C}_{6} \mathrm{H}_{6} \mathrm{Br}$ & $\mathrm{N}_{2} \mathrm{O}_{3}$ & $\mathrm{C}_{5} \mathrm{H}_{4}$ & $\mathrm{~N}_{2} \mathrm{O}_{3}$ & $\mathrm{C}_{27} \mathrm{H}_{14} \mathrm{O}_{5} \mathrm{~F}_{2}$ \\
\hline formula wt & 225.03 & 317.92 & & 313.95 & & 313.93 & & 142. & & 456.38 \\
\hline temp $(\mathrm{K})$ & 100 & 100 & & 100 & & 100 & & 100. & & 296 \\
\hline cryst syst & monoclinic & monoclinic & & monoclinic & & monocl & & mon & oclinic & monoclinic \\
\hline space group & $P 2_{1} / c$ & $P 2_{1} / n$ & & $P 2_{1} / n$ & & $P 2_{1} / c$ & & $C 2 / c$ & & $\mathrm{C} 2 / c$ \\
\hline$a(\AA)$ & $7.2700(5)$ & $8.0664(4)$ & & $11.5366(12$ & & 7.5007 & & 12.26 & $688(15)$ & $27.899(4)$ \\
\hline$b(\AA)$ & $15.8111(11)$ & $7.2059(4)$ & & $7.0510(7)$ & & 15.839 & & 6.57 & $1(9)$ & $7.9166(12)$ \\
\hline$c(\AA)$ & $15.3927(11)$ & $16.0550(7)$ & & $12.1692(13$ & & 15.534 & & 14.23 & $23(19)$ & $22.182(2)$ \\
\hline$\alpha(\mathrm{deg})$ & 90 & 90 & & 90 & & 90 & & 90 & & 90 \\
\hline$\beta(\mathrm{deg})$ & $94.238(5)$ & $100.097(3)$ & & $111.987(3)$ & & 94.827 & & 91.18 & $36(2)$ & $122.13(2)$ \\
\hline$\gamma(\operatorname{deg})$ & 90 & 90 & & 90 & & 90 & & 90 & & 90 \\
\hline volume $\left(\AA^{3}\right)$ & $1764.5(2)$ & $918.75(8)$ & & $917.90(17)$ & & 1838.9 & & 1148 & $6(3)$ & $4148.9(10)$ \\
\hline$Z$ & 8 & 4 & & 4 & & 8 & & 8 & & 8 \\
\hline$\rho\left(\mathrm{g} / \mathrm{cm}^{3}\right)$ & 1.694 & 2.298 & & 2.272 & & 2.268 & & 1.64 & & 1.461 \\
\hline$\mu\left(\mathrm{mm}^{-1}\right)$ & 0.710 & 8.793 & & 8.807 & & 8.776 & & 0.13 & & 0.113 \\
\hline$F(000)$ & 912.0 & 568.0 & & 600.0 & & 1095.0 & & 592. & & 1872.0 \\
\hline no. of rflns collected & 28882 & 5570 & & 6579 & & 68577 & & 8461 & & 71749 \\
\hline goodness of fit on $F^{2}$ & 1.015 & 1.034 & & 1.016 & & 1.010 & & 1.015 & & 1.120 \\
\hline final $R$ indexes $(I>2 \sigma(I))$ & $\begin{array}{l}\mathrm{R} 1=0.0412 \\
\quad \mathrm{wR} 2=0.0828\end{array}$ & $\begin{array}{l}\mathrm{R} 1=0.0252 \\
\quad \mathrm{wR} 2=0.0503\end{array}$ & & $\begin{array}{l}\mathrm{R} 1=0.02 \\
\mathrm{wR} 2=0\end{array}$ & $\begin{array}{l}6, \\
0510\end{array}$ & $\begin{array}{l}\mathrm{R} 1=0 \\
\mathrm{wR} 2\end{array}$ & $\begin{array}{l}269 \\
0.0477\end{array}$ & $\begin{array}{r}\mathrm{R} 1= \\
\mathrm{wR}\end{array}$ & $\begin{array}{l}0.0443 \\
2=0.0930\end{array}$ & $\begin{array}{l}\mathrm{R} 1=0.0608 \\
\quad \mathrm{wR} 2=0.1941\end{array}$ \\
\hline final $R$ indexes (all data) & $\begin{array}{l}\mathrm{R} 1=0.0732, \mathrm{wR} 2 \\
=0.0956\end{array}$ & $\begin{aligned} \mathrm{R} 1 & =0.0356, \mathrm{w} \\
= & 0.0538\end{aligned}$ & & $\begin{array}{r}\mathrm{R} 1=0.036 \\
=0.0542\end{array}$ & 3, wR2 & $\begin{array}{r}\mathrm{R} 1=0 \\
=0.0\end{array}$ & $\begin{array}{l}5548, w R 2 \\
26\end{array}$ & $\begin{array}{r}\mathrm{R} 1= \\
=\mathrm{C}\end{array}$ & $\begin{array}{l}0.0729, \text { wR2 } \\
.1059\end{array}$ & $\begin{array}{l}\mathrm{R} 1=0.0717, \mathrm{wR} 2 \\
=0.2054\end{array}$ \\
\hline CCDC no. & 2006594 & 2006596 & & 2006595 & & 200659 & & 2006 & 597 & 2006598 \\
\hline
\end{tabular}

DSC analyses were carried out with a Mettler Toledo DSC600 hot stage $\left(10{ }^{\circ} \mathrm{C} / \mathrm{min}\right)$. Aluminum oxide crucibles were used for all samples during all thermal analyses, and the instrument was calibrated using indium as a standard; an empty crucible was used as a reference. Data acquisitions were carried out under a flow of $\mathrm{N}_{2}\left(100 \mathrm{~mL} \mathrm{~min}^{-1}\right)$ with a heating rate of $10{ }^{\circ} \mathrm{C} \mathrm{min}^{-1}$. ${ }^{1} \mathrm{H}$ NMR spectra were recorded at ambient temperature on a Bruker AV-400 spectrometer, at $400 \mathrm{MHz}$. The same instrument was used for recording ${ }^{13} \mathrm{C}$ and ${ }^{19} \mathrm{~F}$ NMR spectra. All chemical shifts in the Supporting Information are given in ppm. DMSO- $d_{6}$ was used as a solvent.

The single-crystal X-ray data were collected with a Bruker SMART APEX II CCD area detector diffractometer, equipped with a graphite monochromator and Mo K $\alpha$ radiation $(\lambda=0.71073 \AA)$ and often a KRYOFLEX apparatus keeping the crystals at $100 \mathrm{~K}$ during data collection. Cell refinement and data reduction were done with Bruker
SAINT. Structure solutions were performed with Olex $2^{53}$ using charge-flipping methods and Fourier analysis, and refinements were performed by full-matrix least-squares methods based on $F^{2}$ implemented in SHELXL 2014. ${ }^{54}$ Drawings were prepared using Mercury software. ${ }^{55}$ Essential crystal and refinement data are reported in Table 1.

\section{RESULTS AND DISCUSSION}

The pattern of close contacts observed in crystals of halobarbituric derivatives $\mathbf{1} \mathbf{a}-\mathbf{m}$ is related in a straightforward manner to the electronic features indicated by modeling (see below). The central part of the ring is positive due to the collective effect of the anisotropic distribution of the electronic density at each ring atom, ${ }^{6}$ the $\sigma$ - and $\pi$-holes at ring carbons 
probably playing a major role. Oxygen atoms are negative, imidic hydrogens are positive, ${ }^{56}$ and chlorine and bromine atoms have positive $\sigma$-holes. ${ }^{12}$ The specific close contacts present in crystals of $1 \mathbf{a}-\mathbf{m}$ are numerous and are of different types; some vary from one compound to another, ${ }^{57}$ while others are invariably observed whenever the groups involved are present. The focus in this paper is on these latter contacts.

Crystallographic Analyses. Similar to crystals of unsubstituted barbituric acid ${ }^{58}$ and its derivatives having one or two alkyl and/or aryl groups on $\mathrm{C} 5,{ }^{59} \mathrm{~N}-\mathrm{H} \cdots \mathrm{O}$ hydrogen bonds (HBs) are observed in crystals of all dihalobarbituric acids 1 containing $\mathrm{N}-\mathrm{H}$ group(s). The $\mathrm{HB}$ acceptor can be the oxygen atom of a carbonyl group in a neighboring barbituric molecule or the oxygen of a cocrystallized water molecule (e.g., 1g,h,k), and adducts with different 1D, 2D, or $3 \mathrm{D}$ topologies are formed (Figure 1). ${ }^{60}$ Several HBs are

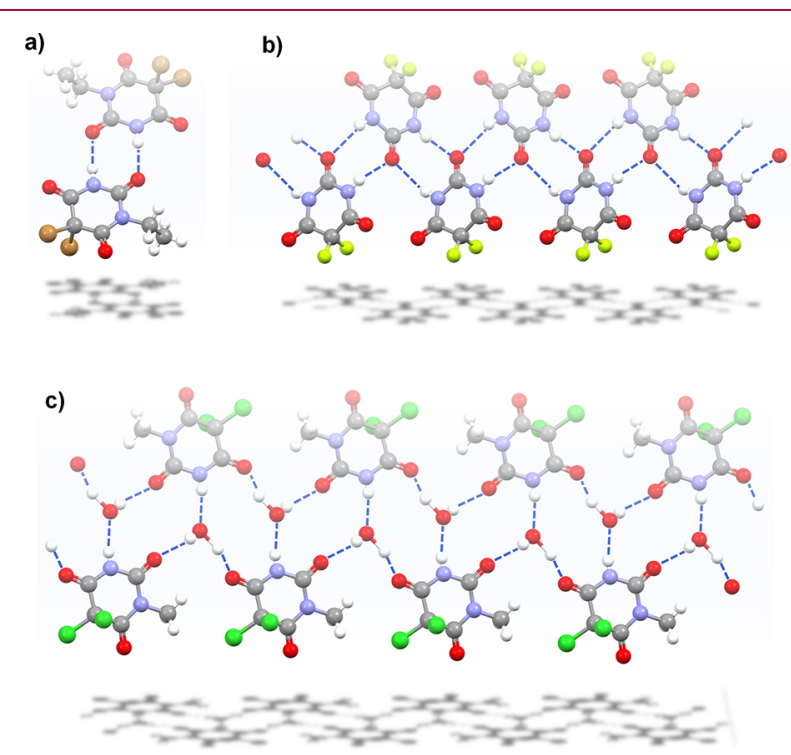

Figure 1. Ball and stick representations (Mercury 4.3.1) of the hydrogen-bonded dimer (a) and ribbons (b) present in crystals of 5,5dibromo- $\mathrm{N}$-ethyl barbituric acid (11) and 5,5-difluoro barbituric acid (1a) thanks to the antiparallel pairing of $\mathrm{C}(=\mathrm{O})-\mathrm{NH}$ functionalities of adjacent molecules and hydrogen-bonded ribbons (c) formed by water molecules which are bridging 5,5-dichloro- $N$-methyl barbituric acid (1g) molecules. HBs are blue dotted lines. Color coding for atoms: whitish, hydrogen; gray, carbon; red, oxygen; blue, nitrogen; brown, bromine; yellowish green, fluorine; green, chlorine.

present in the unit cell of all dihalobarbituric acids $\mathbf{1}$ having $\mathrm{NH}$ group(s), and they are quite short (e.g., the normalized contacts ${ }^{61} \mathrm{Nc}$ of $\mathrm{N}-\mathrm{H} \cdots \mathrm{O}$ separations in $\mathbf{1 k}, \mathbf{1 h}$, and $\mathbf{1 b}, \mathbf{c}$ are as small as $0.73,0.77$, and 0.80 , respectively). It seems therefore that the observed HBs are fairly strong interactions which play a nonminor role in determining the adopted crystal packings. ${ }^{56}$

Chlorinated and brominated dihalobarbituric acids form short $\mathrm{Cl} / \mathrm{Br} \cdots \mathrm{O} \mathrm{HaBs}^{12}{ }^{12} \mathrm{Br} \cdots \mathrm{O} \mathrm{HaBs}$ tend to occur more frequently and to be shorter and closer to linearity than $\mathrm{Cl} \cdots \mathrm{O}$ $\mathrm{HaBs}$ (Figure 2). This is consistent with the behavior observed in crystals of other geminal dichloro and dibromo derivatives ${ }^{56,62-64}$ and with the electrostatic potential at the $\sigma$-hole that is approximately on the elongation of the $\mathrm{C}-\mathrm{Cl} / \mathrm{Br}$ covalent bonds (vide infra). For instance, in 5,5-dibromo- $N$ methyl barbituric acid ( $1 \mathbf{k})$, the $\mathrm{Br} \cdots \mathrm{O}$ distance is as short as $301.2 \mathrm{pm}$ (corresponding to an Nc value of 0.89 ) and the C-

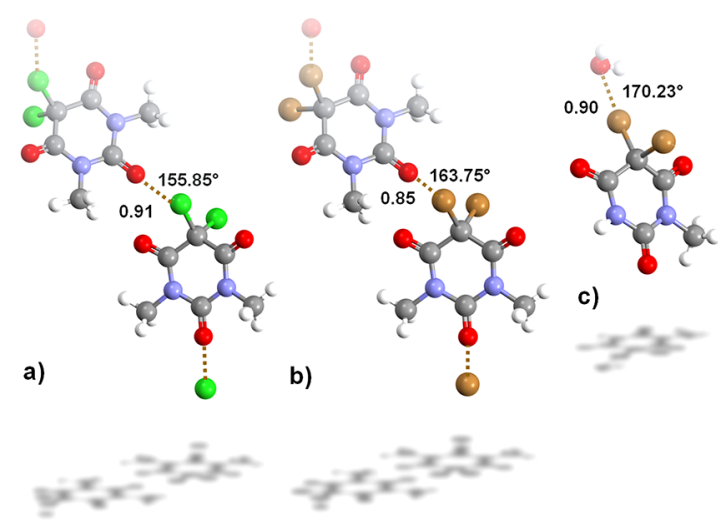

Figure 2. Ball and stick representations (Mercury 4.3.1) of HaBs in 5,5-dichloro- $N, N$-dimethyl barbituric acid (1i) (a), 5,5-dibromo- $N, N$ dimethyl barbituric acid (1m) (b), and 5,5-dibromo- $N$-methyl barbituric acid (1k) (c). HaBs are brown dotted lines. Color coding for atoms: whitish, hydrogen; gray, carbon; red, oxygen; blue, nitrogen; green, chlorine; brown, bromine.

$\mathrm{Br} \cdots \mathrm{O}$ angle is $170.23^{\circ}$, while in the 5,5-dichloro analogue $\mathbf{~} \mathrm{g}$ the $\mathrm{Cl} \cdots \mathrm{O} \mathrm{HaB}$ distance is $314.9 \mathrm{pm}(\mathrm{Nc}=0.96)$ and the $\mathrm{C}-$ $\mathrm{Cl} \cdots \mathrm{O}$ angle is $165.14^{\circ}$.

Molecules of 5,5-dihalobarbituric acids $1 \mathbf{a}-\mathbf{m}$ adopt in the crystals an opened "envelope" conformation wherein the three carbonyl groups and the two nitrogen atoms are nearly coplanar, while C5 is slightly out of the plane with one halogen atom in a quasi-axial and the other in a quasi-equatorial position. In all crystals an oxygen atom sits over the barbituric acid's face opposite to the quasi-axial halogen, typically with an offset from the center of the ring, and forms close contacts with the atoms of the underlying ring in their regions of depleted electronic density. This oxygen is of a barbituric carbonyl group except for 5,5-dichloro- $N$-ethyl barbituric acid (1h), which crystallized as a monohydrate and the oxygen sitting over the face of barbituric acid is that of a water molecule.

The oxygen above the barbituric acid face frequently forms close contacts with one or both of the imide nitrogen atoms of the underlying barbituric acid molecule (Figure 3). Carbonyl

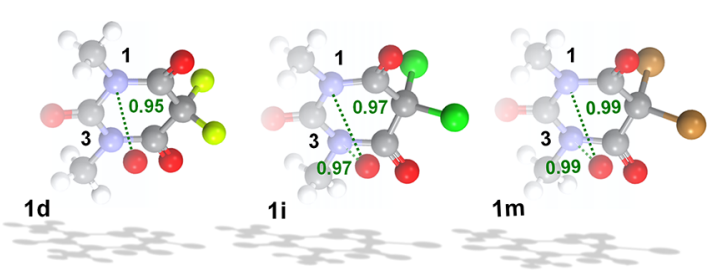

Figure 3. Ball and stick representations (Mercury 4.3.1) of PnBs in 5,5-difluoro- $N, N$-dimethyl barbituric acid (1d) and its 5,5-dichloro and 5,5-dibromo analogues $\mathbf{1 i}, \mathbf{m}$ (from left to right). $\mathrm{PnBs}$ are green dotted lines. Nc values are reported close to the bond. Color coding for atoms: whitish, hydrogen; gray, carbon; red, oxygen; blue, nitrogen; yellowish green, fluorine; green, chlorine; brown, bromine.

groups withdraw electronic density from these nitrogen atoms to the point that they behave as electrophilic sites. It is thus possible to rationalize the close $\mathrm{N} \cdots \mathrm{O}$ contacts observed in $\mathbf{1}$ as pnictogen bonds (PnBs). CSD analysis (Conquest 2.0.5) of the interactions formed by imide nitrogen atoms confirms the possibility that they can function as electrophiles (Table S.4). For instance, the electrophilic role played by imide nitrogen atoms in some interactions is unequivocally proven by the fact 
that the atom interacting with the nitrogen can be not only an oxygen or another neutral atom possessing a lone pair but also an anion. ${ }^{65-67}$

In most dihalobarbituric acids $\mathbf{1 a - m}$ (for instance in $\mathbf{1 a -}$ $\mathbf{c}, \mathbf{e}, \mathbf{g}, \mathbf{i}, \mathbf{k})$, the oxygen sitting above the barbituric acid face forms three $\mathrm{C}\left(\mathrm{sp}^{2}\right) \cdots \mathrm{O}$ interactions as it gives rise to close contacts with all three carbonyl groups of the underlying molecule. In all crystals $\mathbf{1 a}-\mathbf{m}$, the same oxygen atom forms close $\mathrm{C}\left(\mathrm{sp}^{3}\right) \cdots \mathrm{O}$ contacts with the dihalo substituted $\mathrm{C} 5$ atom (Table 1 and Figures S.1-S.15). These close contacts can all be rationalized as TtBs. The occurrence of $\mathrm{C}\left(\mathrm{sp}^{3}\right) \cdots \mathrm{O} \mathrm{TtBs}$ in compounds $\mathbf{1}$ is quite common, nearly as common as that of $\mathrm{C}\left(\mathrm{sp}^{2}\right) \cdots \mathrm{O} \mathrm{TtBs}$ and more common than that of $\mathrm{N} \cdots \mathrm{O}$ PnBs. The $\mathrm{C}\left(\mathrm{sp}^{3}\right) \cdots \mathrm{O} \mathrm{TtBs}$ formed in crystals $\mathbf{1 a}-\mathbf{m}$ by the oxygen above the barbituric acid face are $86 \%$ of the maximum possible number of these interactions; the corresponding percentages for $\mathrm{C}\left(\mathrm{sp}^{2}\right) \cdots \mathrm{O} \mathrm{TtBs}$ and for $\mathrm{N} \cdots \mathrm{O}$ PnBs are $90 \%$ and $74 \%$, respectively. This suggests that $\mathrm{sp}^{3}$ and $\mathrm{sp}^{2}$ carbon atoms in $\mathbf{1}$ have a similar tendency to act as electrophilic sites in the solid and this tendency is higher than that of nitrogen atoms.

CSD analyses provide useful information on the effects of halogen atoms on the patterns of $\mathrm{TtBs}$ involving the barbituric acid ring. Eighty crystal structures in the CSD contain barbituric acid derivatives bearing two hydrogen atoms at $\mathrm{C5}$, and they frequently present a pattern of $\mathrm{TtBs}$ similar to that observed in dihalobarbituric acids 1 (Tables S.1-S.3). Specifically, $30 \%$ of them have close $\mathrm{C}\left(\mathrm{sp}^{3}\right) \cdots \mathrm{O}$ contacts involving $\mathrm{C} 5$ and $46 \%$ or $29 \%$ of them show close $\mathrm{C}\left(\mathrm{sp}^{2}\right) \cdots \mathrm{O}$ contacts involving $\mathrm{C} 4 / 6$ or $\mathrm{C} 2$, respectively. These numbers reveal that short $\mathrm{C}\left(\mathrm{sp}^{3}\right) \cdots \mathrm{O}$ contacts involving $\mathrm{C} 5$ occur more frequently in crystals of halogenated derivatives 1 than of the parent barbituric acid compounds bearing two hydrogen atoms on $\mathrm{C} 5$. This is consistent with the fact that the carbon $\sigma$-holes due to $\mathrm{C}-\mathrm{X}$ covalent bonds $(\mathrm{X}=\mathrm{F}, \mathrm{Cl}, \mathrm{Br}$ ) have significantly more positive electrostatic potentials in comparison to those arising from $\mathrm{C}-\mathrm{H}$ covalent bonds. Halogenation favoring the pinning of an oxygen close to $\mathrm{C} 5$, the statistical occurrence of close $\mathrm{C} 4 / 6 \cdots \mathrm{O}$ and $\mathrm{C} 2 \cdots \mathrm{O}$ contacts is also higher for dihalogenated compounds 1 than for the parent dihydro derivatives and the same holds true for the PnBs.

If substituents with low electronegativity are introduced at $\mathrm{C} 5$, the $\mathrm{C} 5 \sigma$-holes resulting from bonds to such substituents are likely to have only weakly positive electrostatic potentials and by far the most important effects caused by the presence of these substituents on the pattern of interactions involving the barbituric acid ring are expected to be those resulting from increased steric hindrance. In the CSD, 6 and 193 structures contain the 5,5-dimethyl- and 5,5-diethylbarbituric acid moieties, respectively, and these compounds adopt a flattened conformation similar to that of 5,5-dihalobarbituric acids 1 . None of these dialkyl-substituted barbituric acids show close $\mathrm{C} 5 \cdots \mathrm{O}$ contacts; structures with close $\mathrm{C} 4 / 6 \cdots \mathrm{O}$ and $\mathrm{C} 2 \cdots \mathrm{O}$ contacts are 1 and 2 for the dimethyl derivatives and 0 and 20 for the diethyl derivatives, respectively (Tables S.1-S.3). These numbers indicate that, if substituents at $\mathrm{C} 5$ do not result in significantly positive $\sigma$-hole potentials on $\mathrm{C} 5$, then the formation of close $\mathrm{C}\left(\mathrm{sp}^{3}\right) \cdots \mathrm{O}$ contacts involving $\mathrm{C5}$ is prevented, the formation of close $\mathrm{C}\left(\mathrm{sp}^{2}\right) \cdots \mathrm{O}$ contacts involving $\mathrm{C} 4 / 6$ is strongly disfavored, and the formation of close contacts involving $\mathrm{C} 2$, the site less close to $\mathrm{C} 5$, is disfavored to a lesser extent. It may be concluded that the tendency of halogen atoms to favor the pinning of a nucleophile close to the barbituric acid face is effective enough to counterbalance the effect of steric hindrance resulting from halogenation, which opposes the close pinning of the nucleophile. This is the case not only for the small and highly electronegative fluorine but also for the large and poorly electron withdrawing bromine.

To have a precise confirmation of these statistical indications, we prepared and analyzed $\mathrm{N}$-methyl barbituric acid $1 n$. In this compound the close $\mathrm{C} 2 \cdots \mathrm{O}$ contact is not present (the corresponding separation is longer than the sum of the carbon and oxygen van der Waals radii, its Nc value being 1.07) and both $\mathrm{C} 5 \cdots \mathrm{O}$ and $\mathrm{C} 4 / 6 \cdots \mathrm{O}$ contacts are longer than the respective contacts in the fluorinated, chlorinated, and brominated analogues $\mathbf{1 b}, \mathbf{g}, \mathbf{k}$. Exact values are reported in Figure 4. The promoting effect of halogenation at C5 on the formation of short $\mathrm{C}\left(\mathrm{sp}^{3}\right) \cdots \mathrm{O}$ and $\mathrm{C}\left(\mathrm{sp}^{2}\right) \cdots \mathrm{O} \mathrm{TtBs}$ is confirmed.

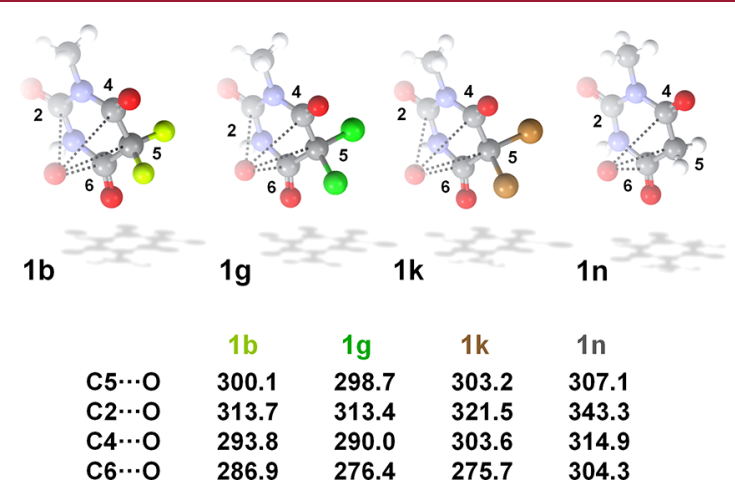

Figure 4. Ball and stick representations (Mercury 4.3.1) of $\mathrm{TtBs}$ in 5,5-difluoro- $N$-barbituric acid (1b) and its dichloro (1g), dibromo (1k), and dihydro analogues (1n, from left to right). Values of $\mathrm{C}\left(\mathrm{sp}^{3}\right) \cdots \mathrm{O}$ and $\mathrm{C}\left(\mathrm{sp}^{2}\right) \cdots \mathrm{O} \mathrm{TtB}$ separations are reported in $\mathrm{pm}$. TtBs are black dotted lines. Color coding for atoms: whitish, hydrogen; gray, carbon; red, oxygen; blue, nitrogen; yellowish green, fluorine; green, chlorine; brown, bromine.

Observed $\mathrm{C}\left(\mathrm{sp}^{3}\right) \cdots \mathrm{O}$ separations in $\mathbf{1 a - m}$ show the directionality typical for $\sigma$-hole TtBs. The oxygen is approximately on the elongation of the $\mathrm{X}_{\text {quasi-axial }}-\mathrm{C} 5$ covalent bond $(\mathrm{X}=\mathrm{F}, \mathrm{Cl}, \mathrm{Br})$. The $\mathrm{X}_{\text {quasi-axial }}-\mathrm{C} \cdots \mathrm{O}$ angles are quite close to linearity; the mean value of the $\mathrm{F}_{\text {quasi-axial }}-\mathrm{C} \cdots \mathrm{O}$ angles in compounds $1 \mathrm{a}-\mathrm{e}$ is $175.38^{\circ}$. Deviation from the expected linearity for $\mathrm{X}-\mathrm{C} \cdots \mathrm{O}$ angles increases with the size of the halogen; the mean value of $\mathrm{Br}_{\text {quasi-axial }}-\mathrm{C} \cdots \mathrm{O}$ angles in compounds $1 \mathbf{j}-\mathbf{m}$ is $165.28^{\circ}$. This is probably related to the fact that on approaching the barbituric ring on the extension of the $\mathrm{X}_{\text {quasi-axial }}-\mathrm{C}$ covalent bond, the oxygen gets close to the most negative region of the quasi-equatorial halogen: namely, the negative belt around its lateral sides. The resulting repulsion diverts the oxygen from the C5 $\sigma$-hole, the effect increasing with the size of the halogen.

The structure of the difluorodiketoindane derivative 2 proves that $\mathrm{TtBs}$ involving dihalogenated $\mathrm{C}\left(\mathrm{sp}^{3}\right)$ sites are robust enough to affect not only the crystal packing of organic molecules but also their conformations in the solid. A short and directional intramolecular $\mathrm{F}-\mathrm{C}\left(\mathrm{sp}^{3}\right) \cdots \mathrm{O} \mathrm{TtB}$ is present in the compound and locks its spatial arrangement (the $\mathrm{C} \cdots \mathrm{O}$ distance is $295.4 \mathrm{pm}$, corresponding to $\mathrm{Nc}=0.92$, and the $\mathrm{F}-$ $\mathrm{C} \cdots \mathrm{O}$ angle is $171.13^{\circ}$ ). 
$\mathrm{C}\left(\mathrm{sp}^{3}\right) \cdots \mathrm{O}$ separations in $\mathbf{1} \mathbf{a}-\mathbf{m}$ are consistently shorter than the sum of the carbon and oxygen van der Waals radii, independent of the nature of the halogen substituents at $\mathrm{C5}$ and of the substituents at nitrogen atoms. For instance, the Nc value of the $\mathrm{C}\left(\mathrm{sp}^{3}\right) \cdots \mathrm{O}$ distance is 0.90 in difluorobarbituric $\operatorname{acid}^{68} \mathbf{1 a}$ and 0.92 and 0.91 in one of the independent molecules in the unit cells of dichloro ${ }^{69}$ and dibromo dimethyl barbituric acids $\mathbf{1 i}, \mathbf{m}$, respectively. $\mathrm{C}\left(\mathrm{sp}^{3}\right) \cdots \mathrm{O}$ contacts involving $\mathrm{C} 5$ are typically shorter than $\mathrm{C}\left(\mathrm{sp}^{2}\right) \cdots \mathrm{O}$ contacts involving $\mathrm{C} 2$ and slightly longer than $\mathrm{C}\left(\mathrm{sp}^{2}\right) \cdots \mathrm{O}$ contacts involving $\mathrm{C} 4 / 6$. For instance, $\mathrm{C} 5 \cdots \mathrm{O}, \mathrm{C} 2 \cdots \mathrm{O}$, and $\mathrm{C} 4 / 6 \cdots \mathrm{O}$ separations are 289.3, 319.2, and 282.2/280.6 pm (the respective Nc values are $0.90,0,88$, and 0.87 ) in difluoro barbituric acid 1a; the corresponding values for 5,5-difluoro- $N$ methyl barbituric acid $\mathbf{1 b}$ and its dichloro and dibromo analogues $\mathbf{1 g}, \mathbf{k}$ are reported in Figure 4. There is usually a strict correlation between bond length and bond strength for similar interactions in structurally similar compounds; C$\left(\mathrm{sp}^{2}\right) \cdots \mathrm{O} \mathrm{TtBs}$ are medium-strength interactions, ${ }^{29-31}$ and it can thus be assumed that the same holds for $\mathrm{C}\left(\mathrm{sp}^{3}\right) \cdots \mathrm{O} \mathrm{TtBs}$ in $\mathbf{1}$. The fact that $\mathrm{C} 5 \cdots \mathrm{O}$ separations in $\mathbf{1 b}, \mathbf{g}, \mathbf{k}$ are shorter than in the hydrogenated parent $\mathbf{1 n}$ indicates that the electronwithdrawing ability of the halogens not only counterbalances but even overcompensates for the effect of the increased steric hindrance due to halogenation and the resulting repulsion between the oxygen involved in $\mathrm{TtB}$ formation and the quasiequatorial halogen of the tetrel-bonded barbituric acid molecule.

These observations allow for rationalizing as $\mathrm{TtBs}$ the interactions formed by dihalomethylene groups of compounds endowed with useful functional properties. For example, Freon-32 is a particularly interesting refrigerant due its zero ozone depletion potential. In its complex with pyridine the nitrogen is opposite to one of the fluorine atoms and the FC... $\mathrm{N}$ separation is below the sum of van der Waals radii $(\mathrm{Nc}=$ 0.97) (Scheme 2). ${ }^{70}$ Similar interactions are observed in

Scheme 2. Structural Formulas of Tetrel-Bonded Systems Involving Freon-32 (Left) and (+)-N-Phenylsulfonyl-3,3camphoryloxaziridine (Right)
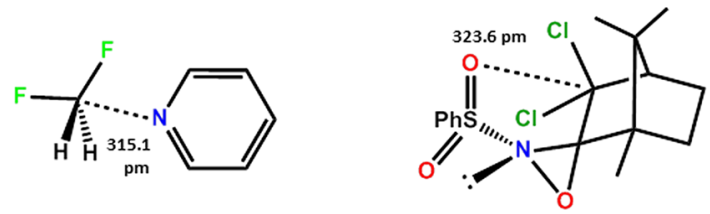

complexes formed by various nucleophiles, water included, with other fluorocarbon refrigerants: e.g., Freon-14. ${ }^{71,72}$ Some oxaziridines function as strong yet selective oxidizing agents. ${ }^{73}$ When $N$-phenylsulfonyl camphoryl oxaziridines are used, oxygen transfer reactions occur enantioselectively and 3,3difluoro, 3,3-dichloro, and 3,3-dibromo derivatives afford higher enantiomeric excesses than the 3,3-dihydro parent compound. $^{62,74}$ It has been shown how the very high enantioselectivity displayed by the 3,3-dichloro derivative is a consequence of a molecular cleft defined by the phenysulfonyl and the dichloromethylene groups, the conformation being locked by a close $\mathrm{Cl}-\mathrm{C}$... OSO separation.

Consistent with the general trend of $\sigma$-hole interactions, ${ }^{7,12,14,17,20}$ shorter contacts are usually more linear. For instance, four independent molecules are present in the unit cell of 5,5-difluoro- $\mathrm{N}, \mathrm{N}$-dimethyl barbituric acid 1d, and the
$\mathrm{C}\left(\mathrm{sp}^{3}\right) \cdots \mathrm{O}$ separations are 289.7 and $304.0 \mathrm{pm}$ in molecules where the $\mathrm{F}-\mathrm{C}\left(\mathrm{sp}^{3}\right) \cdots \mathrm{O}$ angles are 179.37 and $175.60^{\circ}$, respectively.

In all barbituric acid derivatives $\mathbf{1 a}-\mathbf{m}$, the $\mathrm{C}-\mathrm{X}_{\text {quasi-axial }}$ covalent bonds are longer than the $\mathrm{C}-\mathrm{X}_{\text {quasi-equatorial }}$ bonds. The difference between the two bond lengths can be as high as 5.6 and $5.5 \mathrm{pm}$ in one of the two independent molecules present in the unit cells of 5,5-dibromo- $N, N$-dimethylbarbituric acid $1 \mathbf{m}$ and its 5,5-dichloro analogue 1i. $\mathrm{C}-\mathrm{F}$ bonds are stronger than $\mathrm{C}-\mathrm{Cl}$ and $\mathrm{C}-\mathrm{Br}$ bonds, and the differences between $\mathrm{C}-$ $\mathrm{F}_{\text {quasi-axial }}$ and $\mathrm{C}-\mathrm{F}_{\text {quasi-equatorial }}$ bonds is frequently smaller than the corresponding differences in chlorinated and brominated barbituric acids. The greatest difference for the molecules present in the unit cell of 5,5-difluoro- $\mathrm{N}, \mathrm{N}$-dimethylbarbituric acid $\mathbf{1 d}$ is $3.0 \mathrm{pm}$, but it is interesting to observe that in the difluorodiketoindane derivative 2 the $\mathrm{C}-\mathrm{F}$ bond opposite to the tetrel-bonded oxygen is $6.6 \mathrm{pm}$ longer than the other $\mathrm{C}-\mathrm{F}$ bond. This difference in bond lengths may have a molecular origin. The quasi-axial halogen atoms experience greater steric hindrance than the quasi-equatorial halogen, and the greater length of the $\mathrm{C}-\mathrm{X}_{\text {quasi-axial }}$ covalent bond may be a consequence of the need to decrease the repulsive close interactions between the electron clouds of the halogen and barbituric ring atoms. ${ }^{75}$ However, this difference in bond lengths may have also a supramolecular origin. The lengthening of a $\mathrm{C}-\mathrm{X}$ covalent bond opposite to an $\mathrm{HaB}$ is well documented. ${ }^{12,76}$ The formation of $\mathrm{PnBs}^{17}$ and $\mathrm{ChBs}^{7}$ frequently causes an elongation of the covalent bond opposite to these interactions. It has been shown that this can be fully explained in terms of polarization of the electronic densities on the $\sigma$-hole molecules by the electric fields of the negative sites. This difference between the two geminal $\mathrm{C}-\mathrm{X}$ bonds may thus be strictly related to the $\mathrm{TtB}$ formation. It may be even considered a fingerprint of this formation. In several $\mathrm{CF}_{3}$ groups acting as $\mathrm{TtB}$ donor sites, the $\mathrm{C}-\mathrm{F}$ bond opposite to the $\mathrm{TtB}$ is longer than the two other geminal $\mathrm{C}-\mathrm{F}$ bonds. ${ }^{45}$ Usually the shorter the $\sigma$-hole interaction, the greater the lengthening of the opposite covalent bond. Indeed, two independent molecules are present in the unit cell of 5,5chloro- $N, N$-dimethylbarbituric acid $\mathbf{1}$; the two $\mathrm{C}\left(\mathrm{sp}^{3}\right) \cdots \mathrm{O}$ separations are 297.6 and $315.8 \mathrm{pm}$, and the respective differences between $\mathrm{C}-\mathrm{X}_{\text {quasi-axial }}$ and $\mathrm{C}-\mathrm{X}_{\text {quasi-equatorial }}$ covalent bonds are 5.5 and $3.9 \mathrm{pm}$. Similarly, the two $\mathrm{C}\left(\mathrm{sp}^{3}\right) \cdots \mathrm{O}$ separations in the two independent molecules present in 5,5dibromo-N,N-dimethylbarbituric acid $\mathbf{1 m}$ are 293.4 and 329.3 $\mathrm{pm}$ and the respective differences between $\mathrm{C}-\mathrm{X}_{\text {quasi-axial }}$ and $\mathrm{C}-\mathrm{X}_{\text {quasi-equatorial }}$ covalent bonds are 5.6 and $3.3 \mathrm{pm}$.

It has been observed that the formation of $\mathrm{TtBs}$ involving $\mathrm{C}\left(\mathrm{sp}^{3}\right)$ atoms as donor sites may be associated with, or result from, the formation of HBs in which hydrogen atoms on the tetrel-bonded carbon are the HB donor sites. ${ }^{39,44}$ This may be the case in 1n, as the two hydrogen atoms on C5 are quite acidic (the $\mathrm{p} K_{\mathrm{a}}$ of barbituric acid in water is 4.01$)^{77}$ and it can be expected that they are quite effective in forming $\mathrm{HBs}$ and in favoring the approach of oxygen to the $\mathrm{C}\left(\mathrm{sp}^{3}\right)$ atom. In barbituric acid derivatives $\mathbf{1} \mathbf{a}-\mathbf{m}$ no hydrogen atoms are ever bound to $\mathrm{C} 5$, but in all compounds this $\mathrm{C}\left(\mathrm{sp}^{3}\right)$ site functions as a $\mathrm{TtB}$ donor. It is thus proven that $\mathrm{C}\left(\mathrm{sp}^{3}\right)$ atoms can be involved in the formation of short contacts with neutral and lone-pair-possessing atoms also in the absence of ancillary HBs. Importantly, the $\mathrm{C}\left(\mathrm{sp}^{3}\right) \cdots \mathrm{O}$ distance is shorter when the carbon bears two fluorine or chlorine or bromine atoms (namely in $\mathbf{1 b}, \mathbf{g}, \mathbf{k}$ ) than when it bears two hydrogen atoms (in 
1n). As already mentioned, halogenation of C5 increases its electrophilicity.

Molecular Electrostatic Potentials. Close contacts are reliable indicators of attractive interactions in most but not all cases. ${ }^{6}$ The molecular surface electrostatic potentials of 5,5difluoro- $N$-methylbarbituric acid $\mathbf{1 b}$, 5,5-dichloro, and 5,5dibromo analogues $\mathbf{1 g}, \mathbf{k}$, and the parent 5,5-dihydro compound 1n were calculated in order to have information on the electronic features responsible for the short contacts observed in the crystals of barbituric acid derivatives. In Figure 5 we report the computed electrostatic potentials of these compounds. The calculations were at the density functional M06-2X/6-311G(d) level, using the Gaussian 09 program. $^{78}$ The electrostatic potentials were obtained with the WFA-SAS code. $^{79}$

The $\sigma$-hole on the imide hydrogen is the site of most positive electrostatic potential in all four molecules. This accounts for the systematic involvement of $\mathrm{N}-\mathrm{H}$ groups in $\mathrm{HB}$ formation, as $\mathrm{HB}$ donor sites, in all crystals in which the $\mathrm{N}-\mathrm{H}$ group is present.

The second most positive sites are associated with the flat region of barbituric acid rings. The barbituric acid ring in the dihydro compound $1 n$ has a planar conformation. The electrostatic potentials are identical above and below the ring plane. Their most positive values are not exactly above and below the center of the barbituric acid ring but are slightly shifted toward $\mathrm{C} 5$, in an intermediate position between $\mathrm{C} 4$ and C6. The $\mathrm{C} 5-\mathrm{V}_{\mathrm{S} \text {, max }}$ distance is $212 \mathrm{pm}$.

The electrostatic potential at any point in a molecule results from the contributions of all of the nuclei and electrons of the molecule, with those closer to the considered point being more influential. All of the atoms in close proximity to a given $\sigma$ - or $\pi$-hole can thus significantly affect both the magnitude and the location of the positive potential associated with it. A typical example is the nonminor deviation from linearity in pnictogen atoms ${ }^{9}$ of the locally most positive molecular surface potential $\left(V_{\mathrm{S}, \max }\right)$ associated with a $\sigma$-hole. Several cases have also been reported where the positive potentials due to two $\sigma$-holes on the extensions of $\sigma$ covalent bonds on adjacent atoms merge and one single $V_{\mathrm{S}, \max }$ located between the two atoms is observed. ${ }^{3,8,80}$ A site of local most positive potential is normally expected above and below a carbonyl carbon, ${ }^{5,6}$ but it has been reported that the positive potentials associated with two or more $\pi$-holes, on atoms in close proximity, sometimes merge and only two $V_{\mathrm{S} \text {, } \max }$ located on the opposite sides of the molecular plane are observed. This is the case, for instance, in parabanic acid and alloxan, ${ }^{6}$ and a similar behavior is shown by barbituric acids. Three pairs of $V_{\mathrm{S} \text {, max }}$ might be anticipated in 1n corresponding to the three carbonyl groups. However, the positive potentials associated with the three $\pi$-holes in this compound merge and one single $V_{\mathrm{S}, \max }$ is found on each face of dihydrobarbituric acid $\mathbf{1 n}$ (Figure 5a). These $V_{\mathrm{S} \text {, max }}$ are rather strong, approximately above and below the ring center, and are slightly shifted toward C5. The site of one of these $V_{\mathrm{S} \text {, max }}$ is quite close to the site occupied by the oxygen forming the close $\mathrm{C} 4 / 5 / 6 \cdots \mathrm{O}$ contacts found in the crystal of 1 n (the $\mathrm{H}-$ $\mathrm{C} 5 \cdots \mathrm{O}$ angle in the crystal is $170.6^{\circ}$, and the $\mathrm{H}-\mathrm{C} 5 \cdots V_{\mathrm{S}, \max }$ angle calculated in the gas phase is $179.2^{\circ}$ ).

A single $V_{\mathrm{S}, \max }$ is found on each flat region of the molecular surface also in the 5,5-dihalo barbituric acids $\mathbf{1 b}, \mathbf{g}, \mathbf{k}$. This implies that in these derivatives the positive electrostatic potentials associated with the $\pi$-holes of the three carbonyl groups merge and that they further merge with the positive
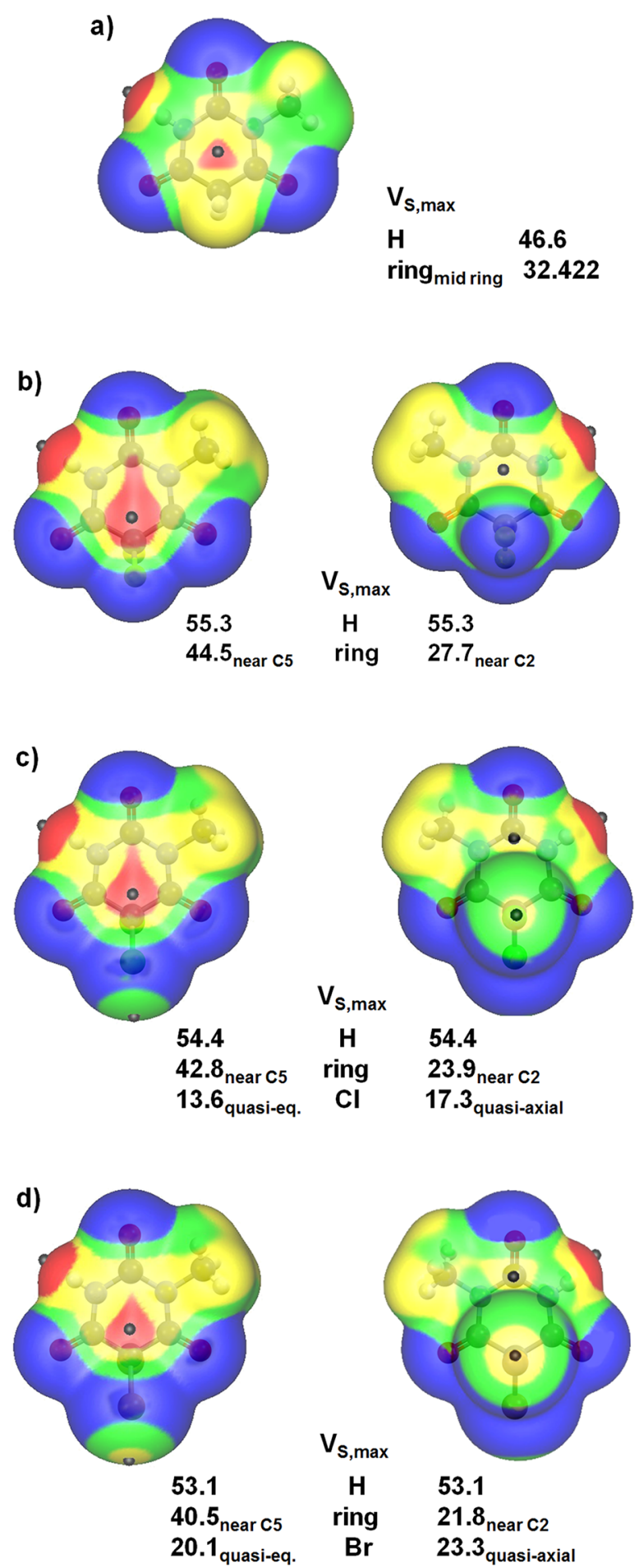

Figure 5. Computed electrostatic potential on the 0.001 au molecular surfaces of the parent 5,5-dihydro compound $1 \mathrm{n}$ (a), 5,5-difluoro- $\mathrm{N}$ methylbarbituric acid $\mathbf{1 b}(\mathrm{b})$, and the 5,5-dichloro and 5,5-dibromo analogues $1 \mathrm{~g}(\mathrm{c})$ and $1 \mathrm{k}(\mathrm{d})$. The flat regions of molecular surfaces are represented; the electrostatic potential is the same on the two faces of $\mathbf{l n}$ and one picture is given, while the electrostatic potential is different on the two faces of $\mathbf{1 b}, \mathbf{g}, \mathbf{k}$ and two pictures are given (face opposite to the quasi-axial halogen on the left). C5 is at the bottom. Electrostatic potential maps are superimposed on the molecular structures; dark gray hemispheres are positions of local most positive electrostatic potential $\left(V_{\mathrm{S}, \max }, \mathrm{kcal} \mathrm{mol}^{-1}\right)$. Color ranges $\left(\mathrm{kcal} \mathrm{mol}^{-1}\right)$ : red, more positive than 28; yellow, between 28 and 14; green, between 14 and 0 ; blue, negative (less than 0 ). 
potentials associated with the carbon $\sigma$-holes opposite to the $\mathrm{C}-\mathrm{X}_{\text {quasi-equatorial }}$ and $\mathrm{C}-\mathrm{X}_{\text {quasi-axial }}$ covalent bonds. In $\mathbf{1 b}, \mathbf{g}, \mathbf{k}$ the most positive potential on one molecular face and its localization are different from the most positive potential and its localization on the other face. These differences are a fingerprint of the specific and different contributions to the electrostatic potentials on the two molecular faces given by the positive potentials associated with the carbon $\sigma$-holes generated by the $\mathrm{C}-\mathrm{X}_{\text {quasi-axial }}$ and the $\mathrm{C}-\mathrm{X}_{\text {quasi-equatorial }}$ covalent bonds. Since $\mathbf{1 b}, \mathbf{g}, \mathbf{k}$ adopt envelope conformations wherein $\mathrm{C5}$ is out of the plane formed by the other five ring atoms, with one halogen being quasi-axial and the other quasi-equatorial, the $V_{\mathrm{S} \text {, max }}$ opposite to the $\mathrm{C}-\mathrm{X}_{\text {quasi-axial }}$ covalent bonds are markedly shifted toward $\mathrm{C} 5$ and those opposite to the $\mathrm{C}-$ $\mathrm{X}_{\text {quasi-equatorial }}$ covalent bonds are even more shifted toward $\mathrm{C} 2$. Both of these dislocations with respect to the parent compound 1n, which has a planar conformation, are a straightforward consequence of the different contributions to the ring $V_{\mathrm{S} \text { max }}$ of the positive carbon potentials associated with the $\sigma$-holes generated by the $\mathrm{C}-\mathrm{X}_{\text {quasi-axial }}$ and the $\mathrm{C}-$ $\mathrm{X}_{\text {quasi-equatorial }}$ covalent bonds.

The $V_{\mathrm{S}, \max }$ on the face opposite to the $\mathrm{C}-\mathrm{X}_{\text {quasi-axial }}$ covalent bond is more positive than that on the face opposite to the $\mathrm{C}-$ $\mathrm{X}_{\text {quasi-equatorial }}$ covalent bond. Consistent with the electronegativities of the respective halogen atoms, the two ring $V_{\mathrm{S} \text {, max }}$ of 5,5-difluoro derivative $\mathbf{1} \mathbf{b}$ are more positive and those of 5,5-dibromo derivative $1 \mathrm{k}$ are less positive than those of 5,5dichloro derivative $\mathbf{1 g}$. Interestingly, the three ring $V_{S, \max }$ opposite to the $\mathrm{C}-\mathrm{X}_{\text {quasi-axial }}$ covalent bond in $\mathbf{1 b}, \mathbf{g}, \mathbf{k}$ and the three opposite to the $\mathrm{C}-\mathrm{X}_{\text {quasi-equatorial }}$ covalent bond are more positive and less positive, respectively, than the ring $V_{S, \max }$ in 1n. The sites of the locally most positive $V_{\mathrm{S} \text {, max }}$ approximately opposite to the quasi-equatorial halogens are close to the positions occupied by the oxygens forming the TtBs and PnBs observed in crystals and discussed above.

Finally it is worth mentioning that, consistent with the $\mathrm{HaBs}$ present in some dichloro and dibromo barbituric acids and with their relative lengths, local $V_{S, \max }$ are found on both halogen atoms of dichloro and dibromo derivatives $\mathbf{1 g}, \mathbf{k}$ (Figure 5), those in $\mathbf{1 g}$ being less positive than those in $\mathbf{1} \mathbf{k}$.

\section{CONCLUSIONS}

Carbon is the element in group 14 that is least prone to form attractive interactions with donors of electron density. ${ }^{5,8,9,19,20,45}$ The results that we have reported provide experimental and computational evidence that not only $\mathrm{C}\left(\mathrm{sp}^{2}\right)$ but also $\mathrm{C}\left(\mathrm{sp}^{3}\right)$ sites can systematically function as $\mathrm{TtB}$ donors and give rise to close contacts with oxygen atoms in crystalline solids. These contacts become shorter when bromine, chlorine, and fluorine residues, i.e. moderately or strongly electron withdrawing residues, are present on the $\mathrm{C}\left(\mathrm{sp}^{3}\right)$ carbon; the contacts are longer in the parent hydrogenated compound. It is proven that the tendency of $\mathrm{C}\left(\mathrm{sp}^{3}\right)$ atoms of some organic derivatives to function as $\mathrm{TtB}$ donors is strong enough to influence the packing of the compounds in crystals: namely, to affect the preferred conformation and/or the network of intermolecular interactions in the crystal lattices.

$\mathrm{C}\left(\mathrm{sp}^{3}\right)$ sites are ubiquitous in organic compounds, and the exact profiling of their tendencies to act as binding sites opens many new opportunities to chemists and biologists in the design and control of a variety of recognition and organization phenomena.
The landscapes of noncovalent interactions formed by several barbituric acid derivatives in their crystals matches with the computed surface electrostatic potentials, and the agreement between computational and experimental results is remarkable. In all cases, one single local maximum of the surface electrostatic potential is present on each molecular face rather than several distinct local maxima. The second most positive local maximum is always on the face having the unusual feature that the carbon $\sigma$-holes on the elongations of the quasi-axial $\mathrm{X}-\mathrm{C} \sigma$ covalent bonds at $\mathrm{C} 5$ merge with the $\pi$ holes perpendicular to the carbonyl carbons at $\mathrm{C} 2, \mathrm{C} 4$, and C6. The localization of the single local maximum of the electrostatic potential on each molecular face is consistent with the $\mathrm{C}\left(\mathrm{sp}^{3}\right) \cdots \mathrm{O}$ and $\mathrm{C}\left(\mathrm{sp}^{2}\right) \cdots \mathrm{O}$ short contacts observed in crystals of barbituric acid derivatives and confirms the crystal engineering described here.

Moving from the seminal role that parabanic acid, alloxan, and triketoindane have had in relation to the short contacts involving $\mathrm{C}\left(\mathrm{sp}^{2}\right)$ sites, ${ }^{46-48}$ we had identified 5,5-dihalobarbituric acid derivatives as serving the same purpose for $\mathrm{C}\left(\mathrm{sp}^{3}\right)$ sites. All features of the $V_{\mathrm{S} \text {, max }}$ confirm the relevance of the positive potentials associated with the $\mathrm{X}-\mathrm{C}$ carbon $\sigma$-holes at $\mathrm{C} 5$ in determining the short $\mathrm{C}\left(\mathrm{sp}^{3}\right) \cdots \mathrm{O}$ and $\mathrm{C}\left(\mathrm{sp}^{2}\right) \cdots \mathrm{O}$ contacts observed in crystals. The ability of halogenated $\mathrm{C}\left(\mathrm{sp}^{3}\right)$ sites to function as $\mathrm{TtB}$ donor sites ${ }^{23}$ is validated. Indeed, a CSD analysis had already enabled us to establish that the $\mathrm{CF}_{3}$ group is particularly tailored to form $\mathrm{TtBs}$ which can affect or control the packing in crystalline solids. ${ }^{45}$

Similar to the case for parabanic acid and alloxan, ${ }^{6,46-48}$ the pattern of short C...O TtBs observed in $\mathbf{1 a}-\mathbf{m}$ strongly affects the crystal packing. It is proven here that this is also the case in compounds where the crystal packing is heavily affected by PnBs formed by imide nitrogen atoms and by several remarkably short, and probably strong, $\mathrm{HBs}$ formed by acidic imide hydrogen atoms. The increased electrophilicity of C5 due to its halogenation affects this robust pattern of interactions at carbon and nitrogen and makes it even more robust than in the nonhalogenated parent molecule. Upon halogenation, the $V_{\mathrm{S}, \max }$ on the flat regions of the molecular surfaces opposite to the pseudoaxial halogens become more positive and the short $\mathrm{C} \cdots \mathrm{O} \mathrm{TtBs}$ occur more frequently and become even shorter.

Reported crystallographic and computational results show that in 5,5-dihalobarbituric acid derivatives the carbon $\sigma$-hole due to an $\mathrm{X}-\mathrm{C}$ covalent bond $(\mathrm{X}=\mathrm{F}, \mathrm{Cl}, \mathrm{Br})$ is even more effective in favoring the approach of an oxygen atom, namely the formation of a $\mathrm{TtB}$, than the corresponding $\mathrm{H}-\mathrm{C}$ covalent bond in the parent compound. This is particularly remarkable if we take into account the repulsive proximity between the tetrel-bonded oxygen and the most negative regions of the quasi-equatorial halogen atoms at $\mathrm{C5}$ in the compounds studied.

\section{ASSOCIATED CONTENT}

\section{Supporting Information}

The Supporting Information is available free of charge at https://pubs.acs.org/doi/10.1021/acs.cgd.0c01429.

Synthesis and characterization of compounds $\mathbf{1}$ and $\mathbf{2}$ $\left({ }^{1} \mathrm{H},{ }^{13} \mathrm{C},{ }^{19} \mathrm{~F}\right.$ NMR, mass, and IR spectra), CSD searches, and additional structural figures (PDF) 


\section{Accession Codes}

CCDC 2006588-2006600 contain the supplementary crystallographic data for this paper. These data can be obtained free of charge via www.ccdc.cam.ac.uk/data_request/cif, or by emailingdata_request@ccdc.cam.ac.uk, or by contacting The Cambridge Crystallographic Data Centre, 12 Union Road, Cambridge CB2 1EZ, UK; fax: +44 1223336033.

\section{AUTHOR INFORMATION}

\section{Corresponding Authors}

Jane S. Murray - Department of Chemistry, University of New Orleans, New Orleans, Louisiana 70148, United States;

Email: jane.s.murray@gmail.com

Giuseppe Resnati - NFMLab, Department of Chemistry, Materials, and Chemical Engineering "Giulio Natta", Politecnico di Milano, I-20131 Milano, Italy; (아이.org/ 0000-0002-0797-9296; Email: giuseppe.resnati@polimi.it

\section{Authors}

Vijith Kumar - NFMLab, Department of Chemistry, Materials, and Chemical Engineering "Giulio Natta", Politecnico di Milano, I-20131 Milano, Italy; 잉o․org/ 0000-0003-0508-3944

Patrick Scilabra - NFMLab, Department of Chemistry, Materials, and Chemical Engineering "Giulio Natta", Politecnico di Milano, I-20131 Milano, Italy; (1) orcid.org/ 0000-0003-1972-620X

Peter Politzer - Department of Chemistry, University of New Orleans, New Orleans, Louisiana 70148, United States; (1) orcid.org/0000-0002-8488-4282

Giancarlo Terraneo - NFMLab, Department of Chemistry, Materials, and Chemical Engineering "Giulio Natta", Politecnico di Milano, I-20131 Milano, Italy; ㅈorcid.org/ 0000-0002-1225-2577

Andrea Daolio - NFMLab, Department of Chemistry, Materials, and Chemical Engineering "Giulio Natta", Politecnico di Milano, I-20131 Milano, Italy; ㅈorcid.org/ 0000-0003-3571-3935

Francisco Fernandez-Palacio - NFMLab, Department of Chemistry, Materials, and Chemical Engineering "Giulio Natta", Politecnico di Milano, I-20131 Milano, Italy

Complete contact information is available at: https://pubs.acs.org/10.1021/acs.cgd.0c01429

\section{Notes}

The authors declare no competing financial interest.

\section{ACKNOWLEDGMENTS}

We are grateful for financial support to Fondazione Cariplo project PHAEDRA, no. 2014-0746.

\section{REFERENCES}

(1) Qu, D.-H.; Wang, Q.-C.; Zhang, Q.-W.; Ma, X.; Tian, H. Photoresponsive Host-Guest Functional Systems. Chem. Rev. 2015, 115, 7543-7588.

(2) Geng, W.-C.; Sessler, J. L.; Guo, D.-S. Supramolecular prodrugs based on host-guest interactions. Chem. Soc. Rev. 2020, 49, 23032315.

(3) Politzer, P.; Murray, J. S. $\sigma$-Hole Interactions: Perspectives and Misconceptions. Crystals 2017, 7, 212.

(4) Politzer, P.; Riley, K. E.; Bulat, F. A.; Murray, J. S. Perspectives on halogen bonding and other $\sigma$-hole interactions: Lex parsimoniae (Occam's Razor). Comput. Theor. Chem. 2012, 998, 2-8.
(5) Murray, J. S.; Lane, P.; Clark, T.; Riley, K. E.; Politzer, P. Mholes, $\pi$-holes and electrostatically-driven interactions. J. Mol. Model. 2012, 18, 541-548.

(6) Occasionally $\sigma$-hole interactions may not be on the extensions of $\sigma$ covalent bonds but between two extensions, and $\pi$-hole interactions, while remaining orthogonal to a planar portion of the molecule, may be offset with respect to a particular atom in it; see: Politzer, P.; Murray, J. S. An Overview of Strengths and Directionalities of Noncovalent Interactions: $\sigma$-Holes and $\pi$-Holes. Crystals 2019, 9, 165.

(7) Scilabra, P.; Terraneo, G.; Resnati, G. The Chalcogen Bond in Crystalline Solids: A World Parallel to Halogen Bond. Acc. Chem. Res. 2019, 52, 1313-1324.

(8) Murray, J. S.; Macaveiu, L.; Politzer, P. Factors affecting the strengths of $\sigma$-hole electrostatic potentials. J. Comput. Sci. 2014, 5, 590-596.

(9) Politzer, P.; Murray, J. S.; Clark, T.; Resnati, G. The $\sigma$-hole revisited. Phys. Chem. Chem. Phys. 2017, 19, 32166-32178.

(10) Terraneo, G.; Resnati, G. Bonding Matters. Cryst. Growth Des. 2017, 17, 1439-1440.

(11) Cavallo, G.; Metrangolo, P.; Pilati, T.; Resnati, G.; Terraneo, G. Naming Interactions from the Electrophilic Site. Cryst. Growth Des. 2014, 14, 2697-2702.

(12) Cavallo, G.; Metrangolo, P.; Milani, R.; Pilati, T.; Priimagi, A.; Resnati, G.; Terraneo, G. The Halogen Bond. Chem. Rev. 2016, 116, 2478-2601.

(13) Aakeroy, C. B.; Bryce, D. L.; Desiraju, G. R.; Frontera, A.; Legon, A. C.; Nicotra, F.; Rissanen, K.; Scheiner, S.; Terraneo, G.; Metrangolo, P.; Resnati, G. Definition of the chalcogen bond (IUPAC Recommendations 2019). Pure Appl. Chem. 2019, 91, 1889-1892.

(14) Biot, N.; Bonifazi, D. Chalcogen-bond driven molecular recognition at work. Coord. Chem. Rev. 2020, 413, 213243.

(15) Grabowski, S. J. Triel bond and coordination of triel centres Comparison with hydrogen bond interaction. Coord. Chem. Rev. 2020, 407, 213171.

(16) Scheiner, S. The Pnicogen Bond: Its Relation to Hydrogen, Halogen, and Other Noncovalent Bonds. Acc. Chem. Res. 2013, 46, 280-288.

(17) Scilabra, P.; Terraneo, G.; Resnati, G. Fluorinated elements of Group 15 as pnictogen bond donor sites. J. Fluorine Chem. 2017, 203, $62-74$.

(18) Bauzá, A.; Frontera, A. $\sigma / \pi$-Hole noble gas bonding interactions: Insights from theory and experiments. Coord. Chem. Rev. 2020, 404, 213112.

(19) Murray, J. S.; Lane, P.; Politzer, P. Expansion of the sigma-hole concept. J. Mol. Model. 2009, 15, 723-729.

(20) Scilabra, P.; Kumar, V.; Ursini, M.; Resnati, G. Close contacts involving germanium and tin in crystal structures: experimental evidence of tetrel bonds. J. Mol. Model. 2018, 24, 37.

(21) Bartashevich, E.; Matveyhuk, Y.; Tsirelson, V. Identification of the Tetrel Bonds between Halide Anions and Carbon Atoms of Methyl Groups Using Electronic Ctriterion. Molecules 2019, 24, 1083.

(22) Grabowski, S. Tetrel bond- $\sigma$-hole bond as a preliminary stage of the $S_{\mathrm{N}} 2$ reaction. Phys. Chem. Chem. Phys. 2014, 16, 1824-1834.

(23) Mani, D.; Arunan, E. The X-C $\cdots \mathrm{Y}(\mathrm{X}=\mathrm{O} / \mathrm{F}, \mathrm{Y}=\mathrm{O} / \mathrm{S} / \mathrm{F} / \mathrm{Cl} /$ $\mathrm{Br} / \mathrm{N} / \mathrm{P}$ ) 'carbon bond' and hydrophobic interactions. Phys. Chem. Chem. Phys. 2013, 15, 14377-14383.

(24) Pennington, W. T.; Hanks, T. H.; Arman, H. D. Halogen Bonding with Dihalogens and Interhalogens. Struct. Bonding (Berlin) 2008, 126, 65-104.

(25) Colin, M. M.; Gaultier de Claubry, H. Sur Le Combinaisons de L'iode Avec Les Substances Végétales et Animales. Ann. Chim. 1814, 90, 87-100.

(26) Reuter, K.; Rudel, S. S.; Buchner, M. R.; Kraus, F.; von Hänisch, C. Crown Ether Complexes of Alkali-Metal Chlorides from $\mathrm{SO}_{2}$. Chem. - Eur. J. 2017, 23, 9607-9617.

(27) Hofmann, A. W. Chemische Untersuchung der Organischen Basen im Steinkohlen-Theeröl. Ann. Chem. Pharm. 1843, 47, 37-87.

(28) Burgi, H. B.; Dunitz, J. D. From crystal statics to chemical dynamics. Acc. Chem. Res. 1983, 16, 153-161. 
(29) Persch, E.; Dumele, O.; Diedrich, F. Molecular recognition in chemical and biological systems. Angew. Chem., Int. Ed. 2015, 54, 3290-3327.

(30) Newberry, R. W.; Raines, R. T. The $\mathrm{n} \rightarrow \pi^{*}$ Interaction. Acc. Chem. Res. 2017, 50, 1838-1846.

(31) Allen, F. H.; Baalham, C. A.; Lommerse, J. M.; Raithby, P. R. Carbonyl-Carbonyl Interactions can be Competitive with Hydrogen Bonds. Acta Crystallogr., Sect. B: Struct. Sci. 1998, 54, 320-329.

(32) Montaña, A. M. The a and Holes. The Halogen and Tetrel Bondings: Their Nature, Importance and Chemical, Biological and Medicinal Implications. Chem. Select. 2017, 2, 9094-9112.

(33) Some stable pentacoordinate carbon species characterized at the end of the $1990 \mathrm{~s}^{34}$ can be considered as early reports on systems containing a very strong $\mathrm{TtB}$ enabled by the $\sigma$-hole opposite to an oxonium residue (a very strongly electron withdrawing substituent). These species were rationalized as hypervalent carbon compounds (10-C-5) and the bonding patterm around the pentavalent carbon atom has been explained in the original manuscript as an interaction between a vacant $\mathrm{C}-\mathrm{X} \sigma^{*}$ orbital and a lone pair of a nucleophile. ${ }^{35}$ Clearly, they can also be understood as $\sigma$-hole interactions involving a $\mathrm{C}\left(\mathrm{sp}^{3}\right)-\mathrm{O}^{+}$moiety.

(34) Akiba, K.-Y.; Yamashita, M.; Yamamoto, Y.; Nagase, S. Synthesis and Isolation of Stable Hypervalent Carbon Compound (10-C-5) Bearing a 1,8-Dimethoxyanthracene Ligand. J. Am. Chem. Soc. 1999, 121, 10644-10645.

(35) Akiba, K.-Y.; Moriyama, Y.; Mizozoe, M.; Inohara, H.; Nishii, T.; Yamamoto, Y.; Minoura, M.; Hashizume, D.; Iwasaki, F.; Takagi, N.; Ishimura, K.; Nagase, S. Synthesis and Characterization of Stable Hypervalent Carbon Compounds (10-C-5) Bearing a 2,6-Bis(psubstituted phenyloxymethyl)benzene Ligand. J. Am. Chem. Soc. 2005, 127, 5893-5901.

(36) Scheiner, S. Ability of IR and NMR Spectral Data to Distinguish between a Tetrel Bond and a Hydrogen Bond. J. Phys. Chem. A 2018, 122, 7852-7862.

(37) Politzer, P.; Murray, J. S.; Clark, T. Halogen bonding and other P-hole interactions: A perspective. Phys. Chem. Chem. Phys. 2013, 15, $11178-11189$.

(38) Mooibroek, T. J. Intermolecular Non-Covalent CarbonBonding Interactions with Methyl Groups: A CSD, PDB and DFT Study. Molecules 2019, 24, 3370.

(39) Mundlapati, V. R.; Sahoo, D. K.; Bhaumik, S.; Jena, S.; Chandrakar, A.; Biswal, H. S. Noncovalent Carbon-Bonding Interactions in Proteins. Angew. Chem., Int. Ed. 2018, 57, 1649616500 .

(40) Trievel, R. C.; Scheiner, S. Crystallographic and Computational Characterization of Methyl Tetrel Bonding in S-AdenosylmethionineDependent Methyltransferases. Molecules 2018, 23, 2965.

(41) Sethio, D.; Oliveira, V.; Kraka, E. Quantitative Assessment of Tetrel Bonding Utilizing Vibrational Spectroscopy. Molecules 2018, 23, 2763.

(42) Southern, S. A.; Bryce, D. L. NMR Investigations of Noncovalent Carbon Tetrel Bonds. Computational Assessment and Initial Experimental Observation. J. Phys. Chem. A 2015, 119, 1189111899.

(43) Gou, Q.; Feng, G.; Evangelisti, L.; Caminati, L. Rotational spectrum of the trtrafluoromethane-ethylene oxide. J. Mol. Spectrosc. 2017, 335, 84-87.

(44) Thomas, S. P.; Pavan, M. S.; Row, T. N. G. Experimental evidence for 'carbon bonding' in the solid state from charge density analysis. Chem. Commun. 2014, 50, 49-51.

(45) Daolio, A.; Scilabra, P.; Terraneo, G.; Resnati, G. C( $\left.\mathrm{sp}^{3}\right)$ atoms as tetrel bond donors: A crystallographic survey. Coord. Chem. Rev. 2020, 413, 213265.

(46) Chu, S. S. C.; Jeffrey, G. A.; Sakurai, T. The crystal structure of tetrachloro-p-benzoquinone (chloranil). Acta Crystallogr. 1962, 15, 661-671.

(47) Bolton, W. The crystal structure of alloxan. Acta Crystallogr. 1964, 17, 147-152.
(48) Bolton, W. The crystal structure of triketoindane (anhydrous ninhydrin). A structure showing close $\mathrm{C}=\mathrm{O} \cdots \mathrm{C}$ interactions. Acta Crystallogr. 1965, 18, 5-10.

(49) In our analysis of crystal structures of $\mathbf{1 a}-\mathbf{m}$ we discuss only interatomic contacts shorter than the sum of van der Waals radii of involved atoms. ${ }^{50}$ In doing so, we adopt the commonly used assumption that these contacts, which we interchangeably denote as short contacts or close contacts, are related to attractive interactions. There are several limitations to the validity of this type of analysis; for instance, when van der Waals radii are used, it is assumed that atoms in molecules are spherical, while radii along the extension of covalent bonds are usually less than perpendicular to the bonds. ${ }^{51,52}$ This type of analysis is nevertheless adopted here, as it is the universally employed approach to identify the hallmarks of the landscape of intermolecular interactions present in a crystal packing.

(50) Bondi, A. van der Waals Volumes and Radii. J. Phys. Chem. 1964, 68, 441-451.

(51) Row, T. N. G.; Parthasarathy, R. Directional preferences of nonbonded atomic contacts with divalent sulfur in terms of its orbital orientations. 2. Sulfur $\cdots$ sulfur interactions and nonspherical shape of sulfur in crystals. J. Am. Chem. Soc. 1981, 103, 477-479.

(52) Batsanov, S. S. Anisotropy of Atomic Van der Waals Radii in the Gas-Phase and Condensed Molecules. Struct. Chem. 2000, 11, 177-183.

(53) Dolomanov, O. V.; Bourhis, L. J.; Gildea, R. J.; Howard, J. A. K.; Puschmann, H. OLEX2: a complete structure solution, refinement and analysis program. J. Appl. Crystallogr. 2009, 42, 339-341.

(54) Sheldrick, G. M. Crystal structure refinement with SHELXL. Acta Crystallogr., Sect. C: Struct. Chem. 2015, 71, 3-8.

(55) Macrae, C. F.; Sovago, I.; Cottrell, S. J.; Galek, P. T. A.; McCabe, P.; Pidcock, E.; Platings, M.; Shields, G. P.; Stevens, J. S.; Towler, M.; Wood, P. A. Mercury 4.0: from visualization to analysis, design and prediction. J. Appl. Crystallogr. 2020, 53, 226-235.

(56) Gelbrich, T.; Rossi, D.; Hafele, C. A.; Griesser, U. J. Barbiturates with hydrogen-bonded layer and framework structures. CrystEngComm 2011, 13, 5502-5509.

(57) For instance, close $\mathrm{C} \cdots \mathrm{O}$ and $\mathrm{N} \cdots \mathrm{O}$ contacts are occasionally formed by oxygen atoms sitting close to the face opposite to the quasi-axial halogen on $\mathrm{C}(5)$ (e.g., in difluoro barbituric acids $\mathbf{1 b}, \mathbf{c}$ ). These interactions are not at all a typical recognition motif of barbituric acids $\mathbf{1}$, are heavily influenced by the steric hindrance of the axial halogen, and are not discussed here.

(58) Tobbens, D. M.; Glinneman, J.; Chierotti, M. R.; van de Streek, J.; Sheptyakov, D. On the high-temperature phase of barbituric acid. CrystEngComm 2012, 14, 3046-3055.

(59) Du, J. J.; Hanrahan, J. R.; Solomon, V. R.; Williams, P. A.; Groundwater, P. W.; Overgaard, J.; Platts, J. A.; Hibbs, D. E. Exploring the Binding of Barbital to a Synthetic Macrocyclic Receptor. A Charge Density Study. J. Phys. Chem. A 2018, 122, 3031-3044.

(60) Tron, A.; Thornton, P. J.; Rocher, M.; Jacquot de Rouville, H.P.; Desvergne, J.-P.; Kauffmann, B.; Buffeteau, T.; Cavagnat, D.; Tucker, J. H. R.; McClenaghan, N. D. Catalytic Enantioselective Desymmetrization of meso-Glutaric Anhydrides Using a Stable $\mathrm{Ni}_{2}-$ Schiff Base Catalyst. Org. Lett. 2014, 16, 1358-1361.

(61) The "normalized contact" $\mathrm{Nc}$ for an interaction between atoms $\mathrm{i}$ and $\mathrm{j}$ is the ratio $D_{\mathrm{ij}} /\left(\mathrm{rvdW}_{\mathrm{i}}+\mathrm{rvdW}_{\mathrm{j}}\right)$, where $D_{\mathrm{ij}}$ is the experimental distance separating atoms $i$ and $j$ and $\operatorname{rvdW}_{i}$ and $\operatorname{rvdW}_{j}$ are the van der Waals radii of atoms $i$ and $j .{ }^{49}$ If the electron donor $j$ is an anionic atom, $\mathrm{rvdW}_{\mathrm{j}}$ is substituted by the Pauling ionic radius of the anion atom $\mathrm{j}$. Nc is a useful indicator, allowing for a more rigorous comparison of separations between different interacting atoms in comparison to absolute values of interaction lengths.

(62) Davis, A. F.; Reddy, R. T.; Han, W.; Carroll, P. J. Chemistry of oxaziridines. 17. $\mathrm{N}$-(Phenylsulfonyl)(3,3-dichlorocamphoryl)oxaziridine: a highly efficient reagent for the asymmetric oxidation of sulfides to sulfoxides. J. Am. Chem. Soc. 1992, 114, 1428-1437. 
(63) Chen, Z.-G.; Zhao, P.-F.; Wang, Y. Aminobromination of $\beta$ Nitrostyrene Derivatives with N,N-Dibromourethane as the Aminobrominating Reagent. Eur. J. Org. Chem. 2011, 2011, 5887-5893.

(64) Pavan, S. M.; Pal, R.; Nagarajan, K.; Row, T. N. G. Characterization of Interactions Involving Bromine in 2,2-Dibromo2,3-dihydroinden-1-one via Experimental Charge Density Analysis. Cryst. Growth Des. 2014, 14, 5477-5485.

(65) In the structure of a pteridinedione derivative the oxygen acting as a nucleophile belongs to a nitrate anion, the $\mathrm{N} \cdots \mathrm{O}$ separation is $260.8 \mathrm{pm}(\mathrm{Nc}=0.79)$, and the two $\mathrm{C}-\mathrm{N} \cdots \mathrm{O}$ angles are 83.47 and $91.23^{\circ}{ }^{66}$ For nonoxygenated anions behaving as $\mathrm{PnB}$ acceptors, in the structures of a maleimide derivative a chloride anion gets close to the imide nitrogen, the $\mathrm{N} \cdots \mathrm{Cl} / \mathrm{F}$ separation is $323.9 \mathrm{pm}(\mathrm{Nc}=0.96)$, the $\mathrm{C}-\mathrm{N} \cdots \mathrm{Cl}$ angle is $84.62^{\circ}$, and the $\mathrm{C}-\mathrm{N} \cdots \mathrm{F}$ angle is $80.09^{\circ} .{ }^{6}$

(66) Jimenez-Pulido, S. B.; Linares-Ordonez, F. M.; MorenoCarretero, M. N. Novel coordination behavior of a pteridinebenzoylhydrazone ligand (BZLMH): Theoretical calculations, XRD structures and luminescence studies. Polyhedron 2009, 28, 26412648.

(67) Wang, Y.; Eichhofer, A.; Weigend, F.; Fenske, D.; Fuhr, O. The coordination behaviour of 2,3-bis(diphenylphosphino)maleic- $N$-phenylimide towards copper, silver, gold and palladium. Dalton Trans. 2019, 48, 6863-6871.

(68) Desmarteau, D. D.; Pennington, W. T.; Resnati, G. Fluorinated Barbituric Acid Derivatives. Acta Crystallogr., Sect. C: Cryst. Struct. Commun. 1994, C50, 1305-1308.

(69) Mallah, E.; Sweidan, K.; Engelmann, J.; Steimann, M.; Kuhn, N.; Maier, M. E. Nucleophilic substitution approach towards 1,3dimethylbarbituric acidderivativesdnew synthetic routes and crystal structures. Tetrahedron 2012, 68, 1005-1010.

(70) Vallejo-López, M.; Spada, L.; Gou, Q.; Lesarri, A.; Cocinero, E.; Caminati, W. Interactions between freons and aromatic molecules: The rotational spectrum of pyridine-difluoromethane. Chem. Phys. Lett. 2014, 591, 216-219.

(71) Mielke, Z.; Coussan, S.; Mierzwicki, K.; Roubin, P.; Sałdyka, M. The Complexes between $\mathrm{CH}_{3} \mathrm{OH}$ and $\mathrm{CF}_{4}$. Infrared Matrix Isolation and Theoretical Studies. J. Phys. Chem. A 2006, 110, 4712-4718.

(72) Maris, A.; Favero, L. B.; Velino, B.; Caminati, W. Pyridine-CF4: A Molecule with a Rotating Cap. J. Phys. Chem. A 2013, 117, 1128911292.

(73) Petrov, V. A.; Resnati, G. Polyfluorinated Oxaziridines: Synthesis and Reactivity. Chem. Rev. 1996, 96, 1809-1823.

(74) Davis, F. A.; Thimma Reddy, R. Asymmetric Oxidation of Simple Selenides to Selenoxides in High Enantiopurity. Stereochemical Aspects of the Allyl Selenoxide/Allyl Selenenate Rearrangement. J. Org. Chem. 1992, 57, 2599-2606.

(75) Gelbrich, T.; Braun, D. E.; Oberparleiter, S.; Schottenberger, H.; Griesser, U. J. The Hydrogen Bonded Structures of Two 5Bromobarbituric Acids and Analysis of Unequal C5-X and C5- $\mathrm{X}^{\prime}$ Bond Lengths $\left(\mathrm{X}=\mathrm{X}^{\prime}=\mathrm{F}, \mathrm{Cl}, \mathrm{Br}\right.$ or $\left.\mathrm{Me}\right)$ in 5,5-Disubstituted Barbituric Acids. Crystals 2016, 6, 47.

(76) Farina, A.; Maille, S. V.; Messina, M. T.; Metrangolo, P.; Resnati, G.; Vecchio, G. Resolution of Racemic 1,2-Dibromohexafluoropropane through Halogen-Bonded Supramolecular Helices. Angew. Chem., Int. Ed. 1999, 38, 2433-2436.

(77) CRC Handbook of Chemistry and Physics, 97th ed.; Haynes, W. M., ed.; CRC Press: 2016; pp 5-89.

(78) Frisch, M. J.; Trucks, G. W.; Schlegel, H. B.; Scuseria, G. E.; Robb, M. A., et al. Gaussian 09, Rev. A.1; Gaussian, Inc.: Wallingford, CT, 2009.

(79) Bulat, F. A.; Toro-Labbé, A.; Brinck, T.; Murray, J. S.; Politzer, P. Quantitative analysis of molecular surfaces: areas, volumes, electrostatic potentials and average local ionization energies. J. Mol. Model. 2010, 16, 1679-1691.

(80) Nayak, S. K.; Kumar, V.; Murray, J. S.; Politzer, P.; Terraneo, G.; Pilati, T.; Metrangolo, P.; Resnati, G. Fluorination promotes chalcogen bonding in crystalline solids. CrystEngComm 2017, 19, 4955-4959. 